\title{
Investment-Specific Technology
}

Shocks and International Business Cycles:

An Empirical Assessment

Federico S. Mandelman, Pau Rabanal, Juan F. Rubio-Ramírez, and Diego Vilán

Working Paper 2010-3

February 2010

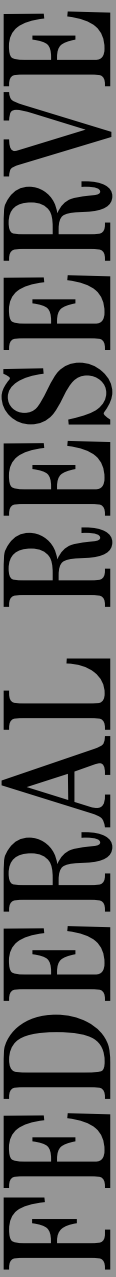




\title{
Investment-Specific Technology Shocks and International Business Cycles: An Empirical Assessment
}

\author{
Federico S. Mandelman, Pau Rabanal, \\ Juan F. Rubio-Ramírez, and Diego Vilán
}

\author{
Working Paper 2010-3 \\ February 2010
}

\begin{abstract}
In this paper, we first introduce investment-specific technology (IST) shocks into an otherwise standard international real business cycle model and show that a thoughtful calibration of them along the lines of Raffo (2009) successfully addresses several of the existing puzzles in the literature. In particular, we obtain a negative correlation of relative consumption and the terms of trade (Backus-Smith puzzle), as well as a more volatile real exchange rate, and cross-country output correlations that are higher than consumption correlations (price and quantity puzzles). Then we use data from the Organisation for Economic Co-operation and Development for the relative price of investment to build and estimate these IST processes across the United States and a "rest of the world" aggregate, showing that they are cointegrated and well represented by a vector error-correction model. Finally, we demonstrate that, when we fit such estimated IST processes into the model, the shocks are actually powerless to explain any of the existing puzzles.
\end{abstract}

JEL classification: E32, F32, F33, F41

Key words: international business cycles, cointegration, investment-specific technology shocks

The authors gratefully acknowledge Jesper Lindé and seminar participants at SCIEA at the Federal Reserve Bank of Dallas for very helpful comments and suggestions. They also thank the National Science Foundation for financial support. The views expressed here are the authors' and not necessarily those of the Federal Reserve Bank of Atlanta, the Federal Reserve System, or the International Monetary Fund (IMF). Any remaining errors are the authors' responsibility.

Please address questions regarding content to Federico Mandelman, Federal Reserve Bank of Atlanta, Research Department, 1000 Peachtree Street, N.E. Atlanta, GA 30309-4470, federico.mandelman@atl.frb.org ; Pau Rabanal, IMF, Research Department, 700 19th Street, N.W., Washington, DC 20431, prabanal@imf.org; Juan F. Rubio-Ramírez, Duke University, Federal Reserve Bank of Atlanta, and FEDEA, 213 Social Sciences Building, P.0. Box 90097, Durham, NC 27708-0097, juan.rubio-ramirez@duke.edu; or Diego Vilán, University of Southern California, 3620 South Vermont Avenue, Kaprielian Hall 300, Los Angeles, CA 90089-0253, vilan@usc.edu.

Federal Reserve Bank of Atlanta working papers, including revised versions, are available on the Atlanta Fed's Web site at www.frbatlanta.org/pubs/WP/. Use the WebScriber Service at www.frbatlanta.org to receive e-mail notifications about new papers. 


\section{Investment-Specific Technology Shocks and International Business Cycles:}

\section{An Empirical Assessment}

\section{Introduction}

Standard international real business cycle (IRBC) models only driven by total factor productivity (TFP) shocks fail to account for at least four features of the data. First, cross-country consumption correlations are generally similar to or lower than cross-country output correlations in the data, whereas existing models typically produce much higher consumption correlations than output correlations. Second, investment and employment tend to be positively correlated across countries, whereas the models predict a negative correlation. Third, the standard setup predicts that the real exchange rate (RER) is positively linked to the ratio of consumption across the two economies, while instead the correlation in the data is negative or close to zero (Backus and Smith, 1993). Fourth, models generate far less volatility in the terms of trade and the RER than in the data (Heathcote and Perri, 2002)

Risk sharing across countries induces strong positive cross-country consumption correlations in the IRBC framework. This result still holds even when the complete markets assumption is replaced by incomplete markets. The efficient response to a TFP shock involves increasing investment and labor supply in the more productive country and reducing them in the less productive country. Thus the cross-country correlations of factor inputs and outputs in the models are lower than those observed empirically. The model also dictates that domestic households consume more relative to their foreign counterparts when their consumption basket is relatively cheap (i.e., when the RER increases), which is at odds with the 
data. Finally, since models produce highly correlated consumption levels, their ratio shows low volatility, and the real exchange rate directly associated with this ratio is consequently less volatile than in the data. The accumulation of these effects creates the four main puzzles described above.

The literature has been energetically trying to fill this gap between theory and data on some of these dimensions, with some success. For example, Chari et al. (2002) show that a monetary economy with monopolistic competition and sticky prices can increase the RER volatility if a high degree of risk aversion is assumed. They also show that in a model with monetary policy shocks only the "Backus-Smith" puzzle cannot be solved regardless of the asset market structure in the model and of the presence of other nominal or real rigidities. Corsetti et al. (2008a and 2008b) show that introducing nontraded goods helps reconcile theory with data on the RER volatility and "Backus-Smith" puzzle dimensions.

Another alternative is to introduce taste shocks as in Stockman and Tesar (1995) and Heathcote and Perri (2007). In particular, Heathcote and Perri (2007) show how this type of demand shock can successfully address the "Backus-Smith" puzzle. However, it is difficult to measure taste shocks in the data. Raffo (2009) instead considers investment-specific technology (IST) shocks, along the guidelines specificatied in Greenwood et al. (1988) and the empirical work of Fisher (2006), and he successfully addresses the four main puzzles. In fact, this type of shock has two appealing features: it resembles a demand shock (given that it directly affects the relative price of capital goods) and it has a clear link to the data. Raffo (2009) cleverly takes advantage of the first feature but does not consider the second. Instead of using the data to parameterize the law of motion of the IST shocks, he thoughtfully calibrates them to match some other observables commonly used in the IRBC literature. 
Our paper follows an alternative approach. First, using data from the OECD, we provide evidence that IST processes for the U.S. and a "rest of the world" (ROW) aggregate have a unit root and are cointegrated. Motivated by this empirical finding, we estimate a vector error correction model (VECM) for the IST processes of the U.S. and the ROW. Second, we add IST shocks that follow the estimated VECM process into an otherwise standard two-country, twogood model with TFP also following a VECM process as described in Rabanal et al. (2009). Our model should be considered an extension of Heathcote and Perri (2002) to consider IST shocks (as in Raffo, 2009) and cointegrated shocks (Rabanal et al., 2009). In that sense, our model is closely related to Ireland (2009), who constructs a two-country stochastic growth model with cointegrated TFP and IST shocks to analyze the macroeconomic performance of both the U.S. and the Euro area. Finally, we simulate the model and analyze the results.

Our results indicate that while a calibration of the IST shocks along the lines of Raffo (2009) would suffice to address the above-mentioned puzzles, the data indicate the contrary: the estimated process for the IST shocks is powerless to solve them. Raffo (2009) calibrates the variance of the IST processes to be almost three times the one characterizing the TFP process. In that case, the IST shocks account for about two-thirds of the variation in output. Instead, our estimation results indicate that the variance of the IST process is about the same size as the variance of the TFP innovations, making the IST shocks quantitatively ineffective.

Our findings do not change even when we consider additional internal amplification mechanisms such as endogenous capital utilization, which facilitate investment demand booms; or GHH preferences, which suppress the wealth effect responsible for dampening the response of the labor supply to productivity innovations and changes in the terms of trade.

In addition to the above-described association with the IRBC literature, our work is also 
related to the growing literature analyzing the usefulness of IST shocks in explaining business cycle fluctuations. As in Altig et al. (2005) and Schmitt-Grohé and Uribe (2008), we find that estimated IST shocks play a minor role in driving business cycle fluctuations. In addition to Raffo's (2009) paper, the lack of thrust of the IST shocks is in conflict with some other studies. For example, Justiniano et al. (2008) estimate that IST shocks are responsible for more than 50 percent of output fluctuations in the U.S. and report a standard deviation of their IST process that is more than four times larger than that of its empirical equivalent. Note, however, that there is a relevant difference between our work and Schmitt-Grohé and Uribe's (2008) work, and that of Justiniano et al. (2008) and Raffo (2009). While both our paper and Schmitt-Grohé and Uribe's estimate the law of motion for IST shocks using the observed relative price of investment, the papers of Justiniano et al. and Raffo do not. Hence, the IST shock can be freely parameterized to fit the properties of other observed macroeconomic variables. But clearly this extra freedom has some empirical implications that are at odds with the data.

The rest of the paper is organized as follows. In section 2 we present the model with cointegrated shocks. In section 3 we describe our data and report estimates for the law of motion of these processes of the U.S. and a ROW aggregate. In section 4 we present the main findings from simulating the model, leaving section 5 for concluding remarks.

\section{The Model}

In this section, we present a standard two-country, two-good IRBC model similar to the one described in Heathcote and Perri (2002). The main difference with respect to the standard 
IRBC literature is the inclusion of IST shocks and the definition of cointegrated processes for both IST and TFP shocks. Following Raffo (2009), and for comparison purposes, we also introduce endogenous capital utilization as in Greenwood et al. (1988) and a quadratic adjustment cost in the capital stock.

In most of the existing literature, productivity processes (neutral and IST) are assumed to be stationary or trend stationary in logs, and they are modelled as a VAR in levels. ${ }^{1,2}$ In this paper, we instead consider $(\log )$ processes that are cointegrated of order $C(1,1)$. This implies that the $(\log )$ processes are integrated of order one but a linear combination is stationary. According to the Granger representation theorem (see Engle and Granger, 1987), our $\mathrm{C}(1,1)$ assumption is equivalent to defining a VECM for the law of motion of the first $(\log )$ differences of the technology processes. It is the case that our $\mathrm{C}(1,1)$ assumption has strong data implications. In section 3.3 we provide empirical evidence that supports our hypothesis.

In each country, a single final good is produced by a representative competitive firm that uses intermediate goods in the production process. These intermediate goods are imperfect substitutes for each other and can be purchased from representative competitive producers of intermediate goods in both countries. Intermediate goods producers use local capital and labor in the production process. The final good can only be locally consumed or invested by consumers; hence, all trade between countries occurs at the intermediate goods level. In addition, consumers trade across countries an uncontingent international one-period riskless

\footnotetext{
${ }^{1}$ Interestingly, Baxter and Crucini (1995) estimate a VECM using TFP processes for the United States and Canada, but they dismiss this evidence when simulating their model. Rabanal et al. (2009) do consider a two-country, two-good IRBC model similar to the one described here but with only cointegrated TFP shocks.

${ }^{2}$ Some important exceptions are Rabanal et al. (2009) Ireland (2009), and Engel and Matsumoto (2009).
} 
bond denominated in units of home-country intermediate goods. We thus assume incomplete markets. In each period of time $t$, the economy experiences one of many finite events $s_{t}$. We denote by $s^{t}=\left(s_{0}, \ldots, s_{t}\right)$ the history of events up through period $t$. The probability, as of period 0 , of any particular history $s^{t}$ is $\pi\left(s^{t}\right)$ and $s_{0}$ is given.

In the remainder of this section, we describe the households' problem, the intermediate and final goods producers' problems, and the VECM processes. Then, we detail market clearing and equilibrium. Finally, we discuss the conditions for the existence of a balanced growth path. In Appendices A.1 and A.2, we explain how to transform the variables in the model to achieve stationarity.

\subsection{Households}

We describe the decision problem faced by home-country households. The problem faced by foreign-country households is similar, and hence, it is not presented because of space considerations. The representative household of the home-country solves

$$
\max _{\left\{C\left(s^{t}\right), L\left(s^{t}\right), X\left(s^{t}\right), K\left(s^{t}\right), D\left(s^{t}\right), u\left(s^{t}\right)\right\}} \sum_{t=0}^{\infty} \beta^{t} \sum_{s^{t}} \pi\left(s^{t}\right) U\left[C\left(s^{t}\right), L\left(s^{t}\right)\right]
$$

subject to the following budget constraint:

$$
\begin{gathered}
P\left(s^{t}\right)\left[C\left(s^{t}\right)+X\left(s^{t}\right)\right]+P_{H}\left(s^{t}\right) \bar{Q}\left(s^{t}\right) D\left(s^{t}\right) \leqslant \\
P\left(s^{t}\right)\left[W\left(s^{t}\right) L\left(s^{t}\right)+u\left(s^{t}\right) R\left(s^{t}\right) K\left(s^{t-1}\right)\right]+P_{H}\left(s^{t}\right)\left\{D\left(s^{t-1}\right)-\Phi\left[D\left(s^{t}\right)\right]\right\}
\end{gathered}
$$


and the law of motion for capital:

$$
K\left(s^{t}\right)=\left\{1-\delta\left[u\left(s^{t}\right)\right]\right\} K\left(s^{t-1}\right)+V\left(s^{t}\right)\left(X\left(s^{t}\right)-\frac{\phi}{2} X\left(s^{t-1}\right)\left[\frac{X\left(s^{t}\right)}{X\left(s^{t-1}\right)}-\Lambda_{X}\right]^{2}\right)
$$

$U\left[C\left(s^{t}\right), L\left(s^{t}\right)\right]$ is the period utility function, ${ }^{3} \beta \in(0,1)$ is the discount factor, $L\left(s^{t}\right) \in$ $(0,1)$ is the fraction of time allocated to work in the home-country, $C\left(s^{t}\right) \geq 0$ are units of consumption of the final good, $X\left(s^{t}\right) \geq 0$ are units of investment, $K\left(s^{t}\right) \geq 0$ is the capital level in the home-country at the beginning of period $t+1 \cdot P\left(s^{t}\right)$ is the price of the home final good, which will be defined below. $W\left(s^{t}\right)$ is the hourly wage in the home-country and $R\left(s^{t}\right)$ is the home-country rental rate of capital, where both are measured in units of the final good. $P_{H}\left(s^{t}\right)$ is the price of the home intermediate good. The depreciation of the stock of capital, $\delta\left[u\left(s^{t}\right)\right]$, is a function of its utilization rate $u\left(s^{t}\right)$. Following Greenwood et al. (1988) we assume that:

$$
\delta\left[u\left(s^{t}\right)\right]=\bar{\delta}+\frac{b}{1+\varepsilon} u\left(s^{t}\right)^{1+\varepsilon},
$$

where $b \geqslant 0$ and $\varepsilon>0$. The parameter $\varepsilon$ represents the elasticity of marginal depreciation with respect to the utilization rate, and $b$ and $\bar{\delta}$ pin down the rate of utilization and the depreciation rate in the steady state. In order to gain some intuition of the effects of each of the considered features, when analyzing the results we will contemplate models without IST shocks, adjustment cost in the capital stock, or an endogenous capital utilization. In particular, when we consider models without a utilization rate of capital, $u\left(s^{t}\right)$ will be set at 1 and $\delta\left[u\left(s^{t}\right)\right]=\delta(1)=\bar{\delta}+\frac{b}{1+\varepsilon}$ for all $s^{t}$ and all $t$.

\footnotetext{
${ }^{3}$ We will consider two types of utility functions when analyzing the results in Section 4 . The standard Cobb-Douglas case, as in Heathcote and Perri (2002), and the GHH preferences as in Raffo (2009).
} 
The parameter $\phi$ controls the elasticity of the adjustment cost in the capital stock to changes in investment. When we consider models without costs of adjustment in the capital stock, $\phi$ will be set to zero.

$V\left(s^{t}\right)$ is the IST shock. In a competitive equilibrium, $V\left(s^{t}\right)^{-1}$ is interpreted as the relative price of capital goods with respect to the price of consumption goods. We will also consider models without IST shocks when analyzing the results. In that case, we will set $V\left(s^{t}\right)=1$ for all $s^{t}$ and all $t$.

The presence of two unit roots makes the model non-stationary (a non-stationary TFP shock will be introduced later). Hence, we rescale the adjustment cost to account for the long-run gross rate of growth of investment along the balanced growth path: $\Lambda_{X}$ (also to be defined later). $D\left(s^{t}\right)$ denotes the holdings of the internationally traded riskless bond that pays one unit of the home-country intermediate good (minus a small cost of holding bonds, $\Phi(\cdot))$ in period $t+1$ regardless of the state of nature. $\bar{Q}\left(s^{t}\right)$ is its price, measured in units of the home intermediate good. Finally, the function $\Phi(\cdot)$ is the arbitrarily small cost of holding bonds measured in units of the home intermediate good. ${ }^{4}$ Following the existing literature, we assume that $\Phi(\cdot)$ takes the following functional form:

$$
\Phi\left[D\left(s^{t}\right)\right]=\frac{\varsigma}{2} Z\left(s^{t-1}\right)\left[\frac{D\left(s^{t}\right)}{Z\left(s^{t-1}\right)}\right]^{2}
$$

We need to include $Z\left(s^{t-1}\right)$ in the adjustment cost function, both dividing $D\left(s^{t}\right)$ and multiplying $\left[\frac{D\left(s^{t}\right)}{Z\left(s^{t-1}\right)}\right]^{2}$ where $Z\left(s^{t}\right)=A\left(s^{t}\right)^{\frac{1}{1-\alpha}} V\left(s^{t}\right)^{\frac{\alpha}{1-\alpha}}$ and $A\left(s^{t}\right)$ is the home-country TFP

\footnotetext{
${ }^{4}$ The $\Phi(\cdot)$ cost is introduced to ensure stationarity of the level of $D\left(s^{t}\right)$ in IRBC models with incomplete markets, as discussed by Heathcote and Perri (2002). We choose the cost to be numerically small, so it does not affect the dynamics of the rest of the variables.
} 
shock. The reason is that $D\left(s^{t}\right)$ will grow at the rate of growth of $Z\left(s^{t-1}\right)$ along the balanced growth path, making the ratio $\frac{D\left(s^{t}\right)}{Z\left(s^{t-1}\right)}$ stationary. Also, since the home-country intermediate good will also grow at the same rate of $Z\left(s^{t-1}\right)$ along the balanced growth path, we need to make the adjustment cost (measured in units of the home intermediate good) grow at that rate in order to induce stationarity.

\subsection{Firms}

\subsubsection{Final goods producers}

The final good in the home-country, $Y\left(s^{t}\right)$, is produced using home intermediate goods, $Y_{H}\left(s^{t}\right)$, and foreign intermediate goods, $Y_{F}\left(s^{t}\right)$, with the following technology:

$$
Y\left(s^{t}\right)=\left[\omega^{\frac{1}{\theta}} Y_{H}\left(s^{t}\right)^{\frac{\theta-1}{\theta}}+(1-\omega)^{\frac{1}{\theta}} Y_{F}\left(s^{t}\right)^{\frac{\theta-1}{\theta}}\right]^{\frac{\theta}{\theta-1}}
$$

where $\omega$ denotes the fraction of home intermediate goods that are used for the production of the home final good and $\theta$ represents the elasticity of substitution between home and foreign intermediate goods. Therefore, the representative final goods producer in the home-country solves the following problem:

$$
\max _{Y\left(s^{t}\right) \geq 0, Y_{H}\left(s^{t}\right) \geq 0, Y_{F}\left(s^{t}\right) \geq 0} P\left(s^{t}\right) Y\left(s^{t}\right)-P_{H}\left(s^{t}\right) Y_{H}\left(s^{t}\right)-P_{F}\left(s^{t}\right) Y_{F}\left(s^{t}\right)
$$

subject to the production function (4). 


\subsubsection{Intermediate goods producers}

The representative intermediate goods producer in the home-country uses home labor and capital in order to produce home intermediate goods and sells her product to both the home and the foreign final good producers. Taking prices of all goods and factor inputs as given, she maximizes profits. Hence, she solves:

$$
\underset{L\left(s^{t}\right) \geq 0, K\left(s^{t-1}\right) \geq 0}{\operatorname{Max}} P_{H}\left(s^{t}\right)\left[Y_{H}\left(s^{t}\right)+Y_{H}^{*}\left(s^{t}\right)\right]-P\left(s^{t}\right)\left[W\left(s^{t}\right) L\left(s^{t}\right)+u\left(s^{t}\right) R\left(s^{t}\right) K\left(s^{t-1}\right)\right]
$$

subject to the production function:

$$
Y_{H}\left(s^{t}\right)+Y_{H}^{*}\left(s^{t}\right)=A\left(s^{t}\right) u\left(s^{t}\right) K\left(s^{t-1}\right)^{\alpha} L\left(s^{t}\right)^{1-\alpha}
$$

where $Y_{H}\left(s^{t}\right)$ is the amount of home intermediate goods sold to the home final goods producers, $Y_{H}^{*}\left(s^{t}\right)$ is the amount of home intermediate goods sold to the foreign final goods producers, and $A\left(s^{t}\right)$ is the TFP shock.

\subsubsection{The VECMs for IST and TFP Shocks}

As mentioned above, we depart from the standard assumption in the IRBC literature and consider processes for both IST and TFP shocks that are cointegrated of order $C(1,1)$ and hence follow a VECM specification. Let us start with the IST shocks, then we will consider the TFP shocks.

We specify the following VECM for the law of motion driving the (log) differences of IST 
processes for both the home and the foreign country:

$$
\left(\begin{array}{c}
\Delta \log V\left(s^{t}\right) \\
\Delta \log V^{*}\left(s^{t}\right)
\end{array}\right)=\left(\begin{array}{c}
c_{V} \\
c_{V}^{*}
\end{array}\right)+\left(\begin{array}{c}
\kappa_{V} \\
\kappa_{V}^{*}
\end{array}\right)\left[\log V\left(s^{t-1}\right)-\gamma_{V} \log V^{*}\left(s^{t-1}\right)-\log \xi_{V}\right]+\left(\begin{array}{c}
\varepsilon^{V}\left(s^{t}\right) \\
\varepsilon^{V, *}\left(s^{t}\right)
\end{array}\right)
$$

where $\left(1,-\gamma_{V}\right)$ is the cointegrating vector and $\xi_{V}$ is the constant in the cointegrating relationship. The shocks $\varepsilon^{V}\left(s^{t}\right) \sim N\left(0, \sigma^{V}\right)$ and $\varepsilon^{V, *}\left(s^{t}\right) \sim N\left(0, \sigma^{V, *}\right)$ are correlated, and $\Delta$ is the first-difference operator. We restrict ourselves to a VECM with zero lag. This assumption is motivated by the empirical results to be presented below.

This VECM law of motion implies that deviations of today's (log) differences of IST shocks with respect to its mean value depend on a function of the ratio of lag home and foreign innovations, $V\left(s^{t-1}\right) /\left[\xi^{V} V^{*}\left(s^{t-1}\right)^{\gamma_{V}}\right]$. The VECM representation implies that $\Delta \log V\left(s^{t}\right)$, $\Delta \log V^{*}\left(s^{t}\right)$, and $\log V\left(s^{t-1}\right)-\gamma_{V} \log V^{*}\left(s^{t-1}\right)-\log \xi^{V}$ are stationary processes.

For the case of the TFP process we follow Rabanal et al. (2009) and consider the following law of motion driving the (log) differences of TFP processes for both the home and the foreign country:

$$
\begin{gathered}
\left(\begin{array}{c}
\Delta \log A\left(s^{t}\right) \\
\Delta \log A^{*}\left(s^{t}\right)
\end{array}\right)=\left(\begin{array}{c}
c_{A} \\
c_{A}^{*}
\end{array}\right)+\rho_{A}^{1}\left(\begin{array}{c}
\Delta \log A\left(s^{t-1}\right) \\
\Delta \log A^{*}\left(s^{t-1}\right)
\end{array}\right)+\rho_{A}^{2}\left(\begin{array}{c}
\Delta \log A\left(s^{t-2}\right) \\
\Delta \log A^{*}\left(s^{t-2}\right)
\end{array}\right) \\
+\left(\begin{array}{c}
\kappa_{A} \\
\kappa_{A}^{*}
\end{array}\right)\left[\log A\left(s^{t-1}\right)-\gamma_{A} \log A^{*}\left(s^{t-1}\right)-\log \xi_{A}\right]+\left(\begin{array}{c}
\varepsilon^{A}\left(s^{t}\right) \\
\varepsilon^{A, *}\left(s^{t}\right)
\end{array}\right) \\
\text { where } \rho_{A}^{1}=\left(\begin{array}{cc}
\rho_{A, 11}^{1} & \rho_{A, 12}^{1} \\
\rho_{A, 21}^{1} & \rho_{A, 22}^{1}
\end{array}\right), \rho_{A}^{2}=\left(\begin{array}{cc}
\rho_{A, 11}^{2} & \rho_{A, 12}^{2} \\
\rho_{A, 21}^{2} & \rho_{A, 22}^{2}
\end{array}\right),\left(1,-\gamma_{A}\right) \text { is the cointegrating vector }
\end{gathered}
$$


and $\xi_{A}$ is the constant in the cointegrating relationship. Finally, $\varepsilon^{A}\left(s^{t}\right) \sim N\left(0, \sigma^{A}\right)$ and $\varepsilon^{A, *}\left(s^{t}\right) \sim N\left(0, \sigma^{A, *}\right)$ are correlated. Note that in this case, we allow a VECM with two lags. This assumption is also motivated by the empirical results to be presented below.

\subsection{Market Clearing}

The model is closed with the following market clearing conditions in the final goods markets:

$$
C\left(s^{t}\right)+X\left(s^{t}\right)=Y\left(s^{t}\right) \text { and } C^{*}\left(s^{t}\right)+X^{*}\left(s^{t}\right)=Y^{*}\left(s^{t}\right)
$$

and the bond markets:

$$
D\left(s^{t}\right)+D^{*}\left(s^{t}\right)=0
$$

\subsection{Equilibrium and Equilibrium Conditions}

Given our laws of motion for shocks defined in section 2.2.3, an equilibrium for this economy is a set of allocations for home consumers, $C\left(s^{t}\right), L\left(s^{t}\right), K\left(s^{t}\right), X\left(s^{t}\right), u\left(s^{t}\right)$, and $D\left(s^{t}\right)$, and foreign consumers, $C^{*}\left(s^{t}\right), L^{*}\left(s^{t}\right), K^{*}\left(s^{t}\right), X^{*}\left(s^{t}\right), u^{*}\left(s^{t}\right)$, and $D^{*}\left(s^{t}\right)$, allocations for home

and foreign intermediate goods producers, $Y_{H}\left(s^{t}\right), Y_{H}^{*}\left(s^{t}\right), Y_{F}\left(s^{t}\right)$ and $Y_{F}^{*}\left(s^{t}\right)$, allocations for home and foreign final goods producers, $Y\left(s^{t}\right)$ and $Y^{*}\left(s^{t}\right)$, intermediate goods prices $P_{H}\left(s^{t}\right)$ and $P_{F}^{*}\left(s^{t}\right)$, final goods prices $P\left(s^{t}\right)$ and $P^{*}\left(s^{t}\right)$, rental prices of labor and capital in the home and foreign-country, $W\left(s^{t}\right), R\left(s^{t}\right), W^{*}\left(s^{t}\right)$, and $R^{*}\left(s^{t}\right)$ and the price of the bond $\bar{Q}\left(s^{t}\right)$ such that $(i)$ given prices, household allocations solve the households' problem; $(i i)$ given prices, intermediate goods producers allocations solve the intermediate goods producers' problem; (iii) given prices, final goods producers allocations solve the final goods producers' problem; 
(iv) and markets clear.

\subsubsection{Equilibrium conditions}

It is useful to define the following relative prices: $\widetilde{P}_{H}\left(s^{t}\right)=\frac{P_{H}\left(s^{t}\right)}{P\left(s^{t}\right)}, \widetilde{P}_{F}^{*}\left(s^{t}\right)=\frac{P_{F}^{*}\left(s^{t}\right)}{P^{*}\left(s^{t}\right)}$ and $R E R\left(s^{t}\right)=\frac{P^{*}\left(s^{t}\right)}{P\left(s^{t}\right)}$. Note that $\widetilde{P}_{H}\left(s^{t}\right)$ is the price of home intermediate goods in terms of home final goods, $\widetilde{P}_{F}^{*}\left(s^{t}\right)$ is the price of foreign intermediate goods in terms of foreign final goods, which appears in the foreign-country's budget constraint, and $R E R\left(s^{t}\right)$ is the RER between the home and foreign countries. In our model the law of one price holds; hence, we have that $P_{H}\left(s^{t}\right)=P_{H}^{*}\left(s^{t}\right)$ and $P_{F}\left(s^{t}\right)=P_{F}^{*}\left(s^{t}\right)$. In the model the only source of RER fluctuations is the presence of home bias.

We now determine the equilibrium conditions implied by the first-order conditions of households, intermediate and final goods producers in the home-country, as well as the relevant laws of motion, production functions, and market clearing conditions. The conditions in the foreign-country are symmetrical and not described here because of space considerations. The marginal utility of consumption and the labor supply are given by:

$$
\begin{aligned}
& U_{C}\left[C\left(s^{t}\right), L\left(s^{t}\right)\right]=\lambda\left(s^{t}\right), \\
& \frac{U_{L}\left[C\left(s^{t}\right), L\left(s^{t}\right)\right]}{U_{C}\left[C\left(s^{t}\right), L\left(s^{t}\right)\right]}=W\left(s^{t}\right),
\end{aligned}
$$

where $U_{x}$ denotes the partial derivative of the utility function $U$ with respect to variable $x$. The first-order conditions with respect to capital and investment deliver:

$$
\mu\left(s^{t}\right)=\beta \sum_{s^{t+1}} \pi\left(s^{t+1} / s^{t}\right)\left\{u\left(s^{t+1}\right) R\left(s^{t+1}\right) \lambda\left(s^{t+1}\right)+\mu\left(s^{t+1}\right)\left(1-\delta\left(u\left(s^{t+1}\right)\right)\right)\right\}
$$


and

$$
\begin{gathered}
\lambda\left(s^{t}\right)=\mu\left(s^{t}\right) V\left(s^{t}\right)\left(1-\phi\left(\frac{X\left(s^{t}\right)}{X\left(s^{t-1}\right)}-\Lambda_{X}\right)\right) \\
+\beta \sum_{s^{t+1}} \pi\left(s^{t+1} / s^{t}\right) \mu\left(s^{t+1}\right) V\left(s^{t+1}\right)\left[\phi\left(\frac{X\left(s^{t+1}\right)}{X\left(s^{t}\right)}-\Lambda_{X}\right) \frac{X\left(s^{t+1}\right)}{X\left(s^{t}\right)}-\frac{\phi}{2}\left(\frac{X\left(s^{t+1}\right)}{X\left(s^{t}\right)}-\Lambda_{X}\right)^{2}\right]
\end{gathered}
$$

where $\pi\left(s^{t+1} \mid s^{t}\right)=\frac{\pi\left(s^{t+1}\right)}{\pi\left(s^{t}\right)}$ is the conditional probability of $s^{t+1}$ given $s^{t}$. When we consider models without an adjustment cost of capital, equation (10) will be substituted by:

$$
\lambda\left(s^{t}\right)=\mu\left(s^{t}\right) V\left(s^{t}\right) .
$$

When we consider models without IST shocks we will set $V\left(s^{t}\right)=1$ for all $s^{t}$ and $t$ in either equation (10) or equation (11) depending on whether we are considering models with or without an adjustment cost of capital.

The first-order condition with respect the capital utilization rate is:

$$
\lambda\left(s^{t}\right) R\left(s^{t}\right)=\mu\left(s^{t}\right) \delta^{\prime}\left(u\left(s^{t}\right)\right)
$$

where, if we take into account the parametrization of $\delta\left(u\left(s^{t}\right)\right)$, we have:

$$
\lambda\left(s^{t}\right) R\left(s^{t}\right)=b \mu\left(s^{t}\right) u\left(s^{t}\right)^{\varepsilon} .
$$

When we consider models without a capital utilization rate, this first-order condition will not be considered and we will set $u\left(s^{t}\right)=1$ for all $s^{t}$ and $t$. Also, when this is the case, $\delta\left(u\left(s^{t}\right)\right)$ will be set equal to $\delta(1)$ for all $s^{t}$ and $t$ in equation (9). 
The optimal choice by households in the home-country with respect to the riskless bond delivers the following expression for its price

$$
\bar{Q}\left(s^{t}\right)=\beta \sum_{s^{t+1}} \pi\left(s^{t+1} \mid s^{t}\right) \frac{\lambda\left(s^{t+1}\right)}{\lambda\left(s^{t}\right)} \frac{\widetilde{P}_{H}\left(s^{t+1}\right)}{\widetilde{P}_{H}\left(s^{t}\right)}-\frac{\Phi^{\prime}\left[D\left(s^{t}\right)\right]}{\beta} .
$$

The risk-sharing condition is given by the optimal choice of the households of both countries for the riskless bond:

$$
\sum_{s^{t+1}} \pi\left(s^{t+1} \mid s^{t}\right)\left[\frac{\lambda^{*}\left(s^{t+1}\right)}{\lambda^{*}\left(s^{t}\right)} \frac{\widetilde{P}_{H}\left(s^{t+1}\right)}{\widetilde{P}_{H}\left(s^{t}\right)} \frac{R E R\left(s^{t}\right)}{R E R\left(s^{t+1}\right)}-\frac{\lambda\left(s^{t+1}\right)}{\lambda\left(s^{t}\right)} \frac{\widetilde{P}_{H}\left(s^{t+1}\right)}{\widetilde{P}_{H}\left(s^{t}\right)}\right]=-\frac{\Phi^{\prime}\left[D\left(s^{t}\right)\right]}{\beta} .
$$

From the intermediate goods producers' maximization problems, we obtain the result that labor and capital are paid their marginal product, where the rental rate of capital and the real wage are expressed in terms of the final good in each country:

$$
W\left(s^{t}\right)=(1-\alpha) \widetilde{P}_{H}\left(s^{t}\right) A\left(s^{t}\right) u\left(s^{t}\right) K\left(s^{t-1}\right)^{\alpha} L\left(s^{t}\right)^{-\alpha}
$$

and

$$
R\left(s^{t}\right)=\alpha \widetilde{P}_{H}\left(s^{t}\right) A\left(s^{t}\right) u\left(s^{t}\right) K\left(s^{t-1}\right)^{\alpha-1} L\left(s^{t}\right)^{1-\alpha} .
$$

From the final goods producers' maximization problem, we obtain the demands of intermediate goods, which depend on their relative price:

$$
Y_{H}\left(s^{t}\right)=\omega \widetilde{P}_{H}\left(s^{t}\right)^{-\theta} Y\left(s^{t}\right)
$$


and

$$
Y_{F}\left(s^{t}\right)=(1-\omega)\left(\widetilde{P}_{F}^{*}\left(s^{t}\right) R E R\left(s^{t}\right)\right)^{-\theta} Y\left(s^{t}\right)
$$

Finally, the goods, inputs, and bond markets clear. Thus:

$$
\begin{gathered}
C\left(s^{t}\right)+X\left(s^{t}\right)=Y\left(s^{t}\right), \\
Y\left(s^{t}\right)=\left[\omega^{\frac{1}{\theta}} Y_{H}\left(s^{t}\right)^{\frac{\theta-1}{\theta}}+(1-\omega)^{\frac{1}{\theta}} Y_{F}\left(s^{t}\right)^{\frac{\theta-1}{\theta}}\right]^{\frac{\theta}{\theta-1}}, \\
Y_{H}\left(s^{t}\right)+Y_{H}^{*}\left(s^{t}\right)=A\left(s^{t}\right) u\left(s^{t}\right) K\left(s^{t-1}\right)^{\alpha} L\left(s^{t}\right)^{1-\alpha},
\end{gathered}
$$

and

$$
D\left(s^{t}\right)+D^{*}\left(s^{t}\right)=0 .
$$

The law of motion of the level of debt is:

$$
\begin{aligned}
\widetilde{P}_{H}\left(s^{t}\right) \bar{Q}\left(s^{t}\right) D\left(s^{t}\right)= & \widetilde{P}_{H}\left(s^{t}\right) Y_{H}^{*}\left(s^{t}\right)-\widetilde{P}_{F}^{*}\left(s^{t}\right) \operatorname{RER}\left(s^{t}\right) Y_{F}\left(s^{t}\right) \\
& +\widetilde{P}_{H}\left(s^{t}\right) D\left(s^{t-1}\right)-\widetilde{P}_{H}\left(s^{t}\right) \Phi\left[D\left(s^{t}\right)\right],
\end{aligned}
$$

and it is obtained using (2) and the fact that intermediate and final goods producers at home make zero profits. Finally, the laws of motion for shocks are as defined in section 2.2.3.

\subsection{Balanced Growth and the Restriction on the Cointegrating Vector}

Equations (7) to (23) and the VECM processes defined in section 2.2.3 characterize the equilibrium in this model. Since we assume that both pairs $\left(\log A\left(s^{t}\right), \log A^{*}\left(s^{t}\right)\right)$ and $\left(\log V\left(s^{t}\right), \log V^{*}\left(s^{t}\right)\right)$ are cointegrated processes, we need to normalize the equilibrium con- 
ditions in order to obtain a stationary system more amenable to study.

The basic idea is to divide most of the home-country variables that have a trend by $Z\left(s^{t-1}\right)$, where $Z\left(s^{t}\right)=A\left(s^{t}\right)^{\frac{1}{1-\alpha}} V\left(s^{t}\right)^{\frac{\alpha}{1-\alpha}}$, and the foreign-country variables by $Z^{*}\left(s^{t-1}\right)$, where $Z^{*}\left(s^{t}\right)=A^{*}\left(s^{t}\right)^{\frac{1}{1-\alpha}} V^{*}\left(s^{t}\right)^{\frac{\alpha}{1-\alpha}}$. One exception is the capital stocks, which are instead divided by $Z\left(s^{t-1}\right) V\left(s^{t-1}\right)$ and $Z^{*}\left(s^{t-1}\right) V^{*}\left(s^{t-1}\right)$ respectively. In Appendices A.1 and A.2, we detail the full set of normalized equilibrium conditions for the Cobb-Douglas and the GHH cases.

For the model to have balanced growth we require some restrictions on preferences, production functions, and the law of motion of the shocks. The restrictions on preferences and technology of King et al. (1988) are sufficient for the existence of balanced growth in a closed economy real business cycle (RBC) model. However, in our two-country model, an additional restriction on the cointegrating vector is needed if the model is to exhibit balanced growth. In particular, we need the ratio $Z\left(s^{t-1}\right) / Z^{*}\left(s^{t-1}\right)$ to be stationary. For example, if the ratio $Z\left(s^{t-1}\right) / Z^{*}\left(s^{t-1}\right)$ were to be non-stationary, the ratio between $Y_{F}\left(s^{t}\right)$ and $Y_{F}^{*}\left(s^{t}\right)$ would also be non-stationary, and consequently, the balanced growth path would not exist. A sufficient condition to guarantee the stationarity of $Z\left(s^{t-1}\right) / Z^{*}\left(s^{t-1}\right)$ is to check for the stationarity of both $A\left(s^{t-1}\right) / A^{*}\left(s^{t-1}\right)$ and $V\left(s^{t-1}\right) / V^{*}\left(s^{t-1}\right)$. Rabanal et al. (2009) indeed show that the first ratio (TFP processes) is stationary. In what follows we focus the analysis on the IST shocks.

When analyzing the results in section 4, we will also consider models in which both IST and TFP shocks are stationary. This is necesary to compare our results with those in the existing literature. In this case, we will not need to normalize the equilibrium conditions (7) to (23). When this is the case, the VECM processes defined in section 2.2.3 will have to be 
replaced. In section 4 we will define the alternative stationary processes to be considered.

\section{Estimation of the VECMs for IST and TFP Shocks}

We present estimates of our VECMs for IST and TFP shocks in this section. We use series for the relative price of investment for the U.S. and the ROW to build our IST shocks. Then, we show that our assumption that the IST processes are cointegrated of order $\mathrm{C}(1,1)$ cannot be rejected in the data. Next, we show that the restriction that the parameter $\gamma_{V}$ be equal to one cannot be rejected in the data either. Finally, we estimate the parameters driving our VECM in order to simulate our model in the next section.

Our VECM for the TFP shocks is directly borrowed from Rabanal et al. (2009). Suffice it to say that Rabanal et al. (2009) show that our assumption that the TFP processes are cointegrated of order $\mathrm{C}(1,1)$ cannot be rejected in the data and that the restriction that the parameter $\gamma_{A}$ be equal to one cannot be rejected in the data either. For space considerations, for the TFP shocks, we report only the point estimates of the parameters of the VECM. It is important to note that the fact that $\gamma_{V}$ and $\gamma_{A}$ are both statistically not different from one implies that we cannot reject the existence of balanced growth.

\subsection{Data for the IST Shocks}

In order to estimate our VECM for (log) IST shocks we use data for the U.S. and an aggregate for the ROW. The ROW is composed of the U.S.'s most significant trading partners: the 15 countries of the European Monetary Union, Canada, Japan, the United Kingdom, Australia and South Korea. Our sample period goes from 1982:4 to 2007:4. Both for the U.S. and for the ROW, we aim to build $V\left(s^{t}\right)$ using data on investment and consumption deflators. In 
particular, for the U.S. the shock $V\left(s^{t}\right)$ is defined as:

$$
\text { U.S._Consumption_deflator } \text { flU.S._Investment_deflator }_{t},
$$

while for the ROW $V^{*}\left(s^{t}\right)$ is defined as:

$$
\sum_{\text {country_i }} \text { weight_country_i } i_{t} *\left(\frac{\text { country_i_Consumption_de } \text { flator }_{t}}{\text { country_i_Investment_deflator }_{t}}\right)
$$

where country_ $i$ belongs to the set European Union, Canada, Japan, the United Kingdom, Australia and South Korea and weight_country_ $i_{t}$ is the trade weight of a particular country at time $t$.

The particular deflators being used are now described. For the U.S. we use the Personal Consumption Expenditure (PCE) deflator as our consumption deflator and the Gross Domestic Investment deflator as our investment deflator. Both series are derived directly from the National Income and Product Accounts (NIPA) and provided by the Bureau of Economic Analysis (BEA). For Japan, we employ the Private final consumption expenditure and the Private-sector capital formation deflator series obtained from the Cabinet Office. In the case of Canada, we use the Personal expenditure on consumer goods and services deflator and the Business gross fixed capital formation deflator series. Both series can be obtained from Canada's statistical agency, "Statistics Canada." For the UK, we use the Final consumption expenditure deflator and the Gross fixed capital formation deflator taken from the UK national statistics. The deflators for Australia are derived from the Australian Bureau of Statistics. The particular series used were the Households final Consumption Expenditure and 
the Gross Fixed Capital formation implicit price deflators. For South Korea we use the Final Consumption Expenditure deflator and Gross Capital Formation deflator series retrieved from the Navi-Data database provided by the Korean National Statistical Office. Finally, for the EMU-15 countries, we employ the Consumption Deflator and the Gross Investment deflator from the AWM Database constructed by the European Central Bank.

\subsection{Integration and Cointegration Properties of the IST Shocks}

In this section, we present evidence supporting our assumption that the (log) IST processes for the U.S. and the ROW are cointegrated of order $\mathrm{C}(1,1)$. We will first empirically support the unit root assumption for the univariate processes and then we will test for the presence of cointegrating relationships using the Johansen (1991) procedure.

Table 1 presents unit root test results for the (log) IST processes for the U.S. and ROW. The lag length is chosen using the Schwarz criterion. In each case a constant and a trend are included in the specification. None of the tests can reject the null hypothesis of unit root at the 5 percent critical value. ${ }^{5}$ This is the case for the U.S. and the ROW. Using the same tests, there is also strong evidence that the first difference of the (log) IST processes for the U.S. is stationary. All the tests reject the null hypothesis of a unit root at the 5 percent critical value. For the ROW the evidence of stationarity of the first difference is weaker. Only the ADF test rejects clearly at the 5 percent and DF-GLS marginally does not reject at the 10 percent critical value. The rest of the tests cannot reject. So, there is strong evidence that the (log) IST process for the ROW is integrated, but it is hard to clarify whether it is integrated of order one or two. Given that there is strong evidence that the (log) IST processes for

\footnotetext{
${ }^{5} \mathrm{ADF}$ marginally rejects at 5 percent but does not reject at 10 percent for the ROW.
} 
the U.S. are integrated of order one and, as we show below, there is also strong evidence of a cointegration relationship between the (log) IST processes for the U.S. and the ROW, we take the evidence presented here as evidence in favor of the (log) IST process for the ROW being integrated of order one.

Table 1: Unit Root Tests for IST Shocks

\begin{tabular}{|c|c|c|c|c|c|c|c|c|}
\hline \multicolumn{5}{|c|}{$\log$ U.S. IST } & \multicolumn{4}{|c|}{$\log$ ROW IST } \\
\hline & \multicolumn{2}{|c|}{ Level } & \multicolumn{2}{|c|}{ First Difference } & \multicolumn{2}{|c|}{ Level } & \multicolumn{2}{|c|}{ First Difference } \\
\hline Method & c. value & t-Stat. & c. value & t-Stat. & c. value & t-Stat. & c. value & t-Stat. \\
\hline $\mathrm{ADF}$ & -3.45 & 1.53 & -3.45 & -7.85 & -3.45 & -0.48 & -3.45 & -3.60 \\
\hline DF-GLS & -3.03 & 0.02 & -3.03 & -7.10 & -3.03 & -1.04 & -3.03 & -2.45 \\
\hline $\mathrm{P}_{T^{-}} \mathrm{GLS}$ & 5.64 & 103.86 & 5.64 & 2.37 & 5.64 & 35.42 & 5.64 & 30.03 \\
\hline $\mathrm{MZ}_{\alpha}$ & -17.3 & -0.02 & -17.3 & -44.37 & -17.3 & -5.18 & -17.3 & -1.90 \\
\hline $\mathrm{MZ}_{t}$ & -2.91 & 0.00 & -2.91 & -4.70 & -2.91 & -1.38 & -2.91 & -0.95 \\
\hline MSB & 0.17 & 0.34 & 0.17 & 0.11 & 0.17 & 0.27 & 0.17 & 0.50 \\
\hline
\end{tabular}

Notes: t-Stat. stands for t-Statistic's and c. value is 5 percent critical values. Critical values for the DF-GLS and $\mathrm{P}_{T^{-}}$GLS tests are as in Elliott-Rothenberg-Stock (1996). Critical values for $\mathrm{MZ}_{\alpha}$, $\mathrm{MZ}_{t}$, and MSB are as reported in Ng-Perron (2001) Table 1.

Once we have presented evidence that indicates that the (log) IST for the U.S. and the ROW is well characterized by integrated processes of order one, we now focus on presenting evidence supporting our assumption that the processes are cointegrated. Table 2 presents some statistics calculated from an unrestricted VAR with one lag and a deterministic trend for the two-variables system $\left[\log V\left(s^{t}\right), \log V^{*}\left(s^{t}\right)\right]$ where the number of lags was chosen using the Schwarz criterion. 
Table 2: Cointegration Statistics I

Eigenvalues Modulus

$0.98,0.88$

Table 2 shows absolute value for the two eigenvalues of the VAR implied by the point estimates. If $\log V\left(s^{t}\right)$ and $\log V^{*}\left(s^{t}\right)$ share one common stochastic trend (balanced growth), the estimated VAR has to have a single eigenvalue equal to one and all other eigenvalues have to be less than one. As shown in Table 2, point estimates are in accord with this prediction. But this is not a formal test of cointegration. Table 3 reports results from the unrestricted cointegration rank test using the trace and the maximum eigenvalue methods as defined by Johansen (1991). We assume no VAR intercept but a constant in the cointegration relationship and zero lags. ${ }^{6}$ Clearly, the data strongly support a single cointegration vector.

Table 3: Cointegration Statistics II: Johansen's Test

\begin{tabular}{ccccc}
\hline \hline Number of Vectors & Trace & p-value & Max-Eigenvalue & p-value \\
\hline 0 & 62.61 & 0.00 & 56.75 & 0.00 \\
1 & 5.85 & 0.20 & 5.85 & 0.21 \\
\hline \hline
\end{tabular}

\subsection{The Estimated VECM for IST Shocks}

In the last subsection, we presented evidence that $\log V\left(s^{t}\right)$ and $\log V^{*}\left(s^{t}\right)$ are cointegrated of order $\mathrm{C}(1,1)$. In this subsection we show that the null hypothesis of $\gamma_{V}=1$ cannot be rejected by the data. In fact, the LR test for the null hypothesis $\gamma_{V}=1$ is distributed as a Chi-squared with one degree of freedom and takes value 1.1, clearly smaller than the 5

\footnotetext{
${ }^{6}$ The Johansen (1991) test rejects the existence of a cointegration relationship if we allow for a trend in the VAR or we do not allow for a constant in the cointegration relationship.
} 
percent critical value of 3.84. Conditional on this restriction and assuming zero lags, the VECM estimates are reported in Table $4 .^{7}$

Table 4: The VECM for IST

\begin{tabular}{|c|c|}
\hline$\kappa_{V}$ & $\kappa_{V}^{*}$ \\
\hline $\begin{array}{c}-0.035^{+} \\
(-8.26)\end{array}$ & $\begin{array}{c}-0.017^{+} \\
(-3.68)\end{array}$ \\
\hline
\end{tabular}

Finally, the standard deviation of the innovations $\varepsilon^{V}\left(s^{t}\right)$ and $\varepsilon^{V, *}\left(s^{t}\right)\left(\sigma^{V}\right.$ and $\left.\sigma^{V, *}\right)$ are estimated to be 0.0051 and 0.0052 , respectively. In the simulation, we will assume that $\varepsilon^{V}\left(s^{t}\right)$ and $\varepsilon^{V, *}\left(s^{t}\right)$ are uncorrelated, since this null hypothesis cannot be rejected in the data.

\subsection{The Estimated VECM for TFP Shocks}

As previously mentioned, we do not estimate the VECM model for TFP in this paper. Instead we borrow from Rabanal et al. (2009), who construct TFP series for the U.S. and the ROW and perform three exercises. First, they show that the assumption that the TFP processes are cointegrated of order $\mathrm{C}(1,1)$ cannot be rejected in the data. Second, they show that the restriction that the parameter $\gamma_{A}$ be equal to one also cannot be rejected in the data.

In the IRBC literature, it is typically assumed that the coefficients driving TFP processes are symmetric across countries. Rabanal et al. (2009) present evidence supporting symmetry across the estimated parameters in (6). In particular, they show that (1) balanced growth cannot be rejected for joint TFP processes, (2) the coefficients related to the speed of adjustment in the cointegrating vector are equal and of opposite sign, i.e., $\kappa_{A}=-\kappa_{A}^{*},(3)$

\footnotetext{
${ }^{7}$ We do normalize the (log) IST shocks so that the constant takes a value equal to zero. Hence, we do not report it.
} 
the coefficients of the constant terms are the same, i.e., $c_{A}=c_{A}^{*}$, and (4) they show that symmetry in the coefficients of the VAR is rejected, but they show the parameter estimates of assuming that $\rho_{A, 11}^{1}=\rho_{A, 22}^{1}, \rho_{A, 11}^{2}=\rho_{A, 22}^{2}, \rho_{A, 12}^{1}=\rho_{A, 21}^{1}$, and $\rho_{A, 12}^{2}=\rho_{A, 21}^{2}$, as is the case in most of the literature. Finally, their reported point estimates are:

Table 5: VECM for TFP

\begin{tabular}{cccccc}
\hline \hline$c_{A}$ & $\kappa^{A}$ & $\rho_{A, 11}^{1}$ & $\rho_{A, 11}^{2}$ & $\rho_{A, 12}^{1}$ & $\rho_{A, 12}^{2}$ \\
\hline $\begin{array}{ccccc}0.0071^{+} \\
(5.83)\end{array}$ & $\begin{array}{c}-0.0045^{+} \\
(-2.65)\end{array}$ & $\begin{array}{c}0.2041^{+} \\
(2.97)\end{array}$ & $\begin{array}{c}0.1026 \\
(1.54)\end{array}$ & $\begin{array}{c}0.1035 \\
(1.55)\end{array}$ & $\begin{array}{c}-0.1497^{+} \\
(-2.40)\end{array}$ \\
\hline \hline
\end{tabular}

They estimate the standard deviation of the innovations $\sigma^{A}$ and $\sigma^{A, *}$ is $0.0052 .{ }^{8}$ In the simulation, we will also assume that $\varepsilon^{A}\left(s^{t}\right)$ and $\varepsilon^{A, *}\left(s^{t}\right)$ are uncorrelated, since Rabanal et al. (2009) cannot be reject this null hypothesis.

\section{Results}

In this section we analyze the results. We will solve the model taking a log-linear approximation around the steady state and then we will simulate the model using the two mentioned approaches to parametrize the law of motion of IST shocks: (1) a calibration along the lines of Raffo (2009) and (2) an estimation as described in section 3. As we show below, the implications of the two approaches with respect to the model's ability to solve the above-mentioned puzzles are quite different. While Raffo's (2009) approach can easily account for them, our estimation approach cannot. The reason is that our estimated IST shocks are much less volatile than Raffo (2009) assumes.

\footnotetext{
${ }^{8}$ In Rabanal et al. (2009), the reported standard deviation of $\sigma^{A}$ is 0.0082 . However, they use a model in which technology innovations are labor augmenting: $Y\left(s^{t}\right)=K\left(s^{t-1}\right)^{\alpha}\left(A\left(s^{t}\right) L\left(s^{t}\right)\right)^{1-\alpha}$. The standard deviation in this paper is thus equal to $0.0082 *(1-\alpha)$.
} 


\subsection{Model Parameterization}

Our baseline parameterization follows closely that in Heathcote and Perri (2002). The discount factor $\beta$ is set equal to 0.99 , which implies an annual rate of return on capital of 4 percent. We assume a cost of bond holdings, $\varsigma$, of 1 basis point (0.01). Parameters on technology are fairly standard in the literature. Thus, the capital share of output is set to $\alpha=0.36$, and home bias for home-country intermediate goods is set to $\omega=0.9$, which implies the observed import/output ratio in the steady state for the U.S. As in Raffo (2009), we assume a relatively low value for the elasticity of substitution, $\theta=0.62$. This is the same value used by Corsetti et al. (2008a).

We consider two different period utility functions. First, we analyze Cobb-Douglas preferences as in Heathcote and Perri (2002):

$$
U\left[C\left(s^{t}\right), 1-L\left(s^{t}\right)\right]=\frac{\left\{C\left(s^{t}\right)^{\tau}\left[1-L\left(s^{t}\right)\right]^{1-\tau}\right\}^{1-\sigma}}{1-\sigma} .
$$

When this is the case, we strictly follow Heathcote and Perri (2002) and fix the consumption share, $\tau$, at 0.34 , which also serves to pin down the steady-state value for the households' labor supply at 0.30 . The coefficient of risk aversion, $\sigma$, is set equal to 2. Backus, Kehoe, and Kydland (1992) assume the same value for the latter parameter.

Second, we also consider the Greenwood, Hercowitz and Huffman (GHH) quasilinear preferences specification:

$$
U\left[C\left(s^{t}\right), 1-L\left(s^{t}\right)\right]=\frac{\left\{C\left(s^{t}\right)-\psi L\left(s^{t}\right)^{\nu}\right\}^{1-\sigma}}{1-\sigma} .
$$


Here we follow Raffo (2008) and fix $\nu$ and $\psi$, to 8.01 and 1163.4, so as to obtain the same steady-state value for the households' labor supply and the same labor supply elasticity as in the Cobb-Douglas specification. ${ }^{9}$ The value of $\sigma$ is set to be equal to the Cobb-Douglas case.

As it is standard in the IRBC literature, when we consider capital adjustment costs, we will calibrate $\phi$ so that in the model simulations, the relative standard deviation of investment with respect to output resembles the value in the data. The value of this parameter will change depending on the version of the model we are analyzing. We will describe the different values taken in the subsections.

Similarly, when we consider the capital utilization rate, we will normalize its steady-state value to 1 . The value of $b$ will be set to 0.0351 , since the first-order condition (12) relates $b$ to the steady-state value of the interest rate. The elasticity of marginal depreciation, $\varepsilon$, will be fixed at 1, in line with Baxter and Farr (2001), who rely on estimates provided by Basu and Kimball (1997). Finally, $\bar{\delta}$ will be set to 0.074 , such that $\delta(1)=0.025$.

\subsection{Solving the Puzzles}

We start by showing how the baseline IRBC framework cannot solve the mentioned puzzles. Then, we replicate Raffo's (2009) exercise: we add IST, endogenous capital utilization, and GHH utility. These three features (as long as we calibrate the IST shocks as in Raffo, 2009) will be sufficient to address the four puzzles discussed in the introduction. In order to be close to Raffo's (2009) work, in this subsection we consider stationary shocks.

\footnotetext{
${ }^{9}$ The labor supply elasticity for the Cobb-Douglas $\left(\varepsilon_{C D}\right)$ and GHH specifications $\left(\varepsilon_{G H H}\right)$ are defined as follows: $\varepsilon_{C D}=\frac{\left(1-L_{s s}\right)[1-\tau(1-\sigma)]}{\sigma L_{s s}}, \varepsilon_{G H H}=\frac{1}{\nu-1}$, where $L_{s s}$ is the steady-state value of $L\left(s^{t}\right)$.

Notice that if $\nu=\frac{1+\varepsilon_{C D}}{\varepsilon_{C D}}$, we effectively impose $\varepsilon_{C D}=\varepsilon_{G H H}$. Finally, $\psi$ is adjusted to obtain the desired $L_{s s}$, as implied by the steady-state conditions: $W_{s s}=(1-\alpha)\left(\frac{K_{s s}}{L_{s s}}\right)^{\alpha}=\psi \nu L_{s s}^{\nu-1}$, so that $\psi=\frac{W_{s s}}{\nu L_{s s}^{\nu-1}}$.
} 
The baseline model includes only stationary TFP shocks with Cobb-Douglas preferences, as in Heathcote and Perri (2002). In this case, neither IST shocks, investment adjustment costs, nor endogenous capital utilization is considered. Mimicking this paper, we assume the following stationary VAR(1) to characterize the stationary TFP process:

$$
\begin{aligned}
A\left(s^{t}\right) & =\rho_{A} A\left(s^{t-1}\right)+\rho_{A}^{*} A^{*}\left(s^{t-1}\right)+\varepsilon^{A}\left(s^{t}\right), \\
A^{*}\left(s^{t}\right) & =\rho_{A} A^{*}\left(s^{t-1}\right)+\rho_{A}^{*} A\left(s^{t-1}\right)+\varepsilon^{A, *}\left(s^{t}\right) .
\end{aligned}
$$

where $\rho_{A}=0.97, \rho_{A}^{*}=0.025, \operatorname{Var}\left(\varepsilon_{t}^{A}\right)=\operatorname{Var}\left(\varepsilon_{t}^{A, *}\right)=0.0073^{2}$, and $\operatorname{corr}\left(\varepsilon_{t}^{A}, \varepsilon_{t}^{A, *}\right)=0.29$. The first two rows of table 6(a), 6(b) and 6(c) show Hodrick-Prescott (HP) filtered ( $\lambda=1600)$ moments from the data and those from the baseline IRBC model (M1) obtained with frequencydomain techniques. When comparing both rows, the four "puzzles" that characterize this framework are evident. First, the baseline model tends to predict a relatively high crosscountry consumption correlation, whereas the data indicate that consumption correlations tend to be lower than output correlations. Second, the standard model delivers a standard deviation of the terms of trade and the RER that is much lower than in the data. Backus et al. (1995) refer to these two anomalies as the "quantity" puzzle and "price" puzzle, respectively. The "international comovement" puzzle (Baxter, 1995) addresses the cross-country correlations of factor inputs. Investment and employment are positively correlated across countries, whereas the model delivers a negative correlation. Finally, the "Backus-Smith" puzzle refers to the fact that while models' strong risk-sharing conditions predict a positive (and close to one) correlation between the RER and the ratio of consumption between countries, ${ }^{10}$ the

\footnotetext{
${ }^{10}$ The optimal risk-sharing condition mimicks the behavior of a benevolent social planner who allocates con-
} 
data indicate that such a correlation is negative.

If TFP shocks are stationary, changes in permanent income following asymmetric shocks are small, implying little need for insurance markets. A single international asset allow households to obtain allocations similar to those when markets are complete. However, as discussed in Heathcote and Perri (2002), imposing a stationary technology process does not seem to constitute an important feature to judge the quantitative relevance of the model.

That is, in principle, near-unit-root TFP shocks with no spill overs to the other country can lead to significant changes in relative wealth (and thus relative consumption). In such a context, we could expect large differences between the behavior of the models with incomplete asset markets following the shock. However, the elasticity of substitution is an important additional determinant of the extent to which productivity shocks affect relative wealth. An increase in aggregate productivity in one country (due to a TFP shock) leads to an increase in the relative world supply of the good that country produces. This implies an increase in the terms of trade of the other country, since the good it produces becomes relatively scarcer. Standard trade elasticity values used within the IRBC framework imply that movements in the terms of trade almost exactly offset changes in relative productivity. The absence of sizable changes in relative wealth implies that a single risk-free bond is sufficient to closely replicate the complete markets allocation even when near-unit-root innovations are in place.

The inclusion of IST shocks breaks this logic, since the terms of trade do not necessarily reflect the relative scarcity of production, but instead the relative demand for capital goods this shock triggers. We first proceed by simply activating the stochastic process for the

sumption such that the marginal rate of transformation $\frac{P_{t}^{*}}{P_{t}}=R E R_{t}$ equates the marginal rate of substitution $\frac{U_{c^{*}, t}^{*}}{U_{c, t .}}$ (directly linked to relative consumption). 
IST shock. Let us first assume a near unit-root process (though still stationary) with no spillovers across countries, i.e., $V\left(s^{t}\right)=\rho_{V} V\left(s^{t}\right)+\varepsilon^{V}\left(s^{t}\right), V^{*}\left(s^{t}\right)=\rho_{V} V^{*}\left(s^{t}\right)+\varepsilon^{V^{*}}\left(s^{t}\right)$, such that $\rho_{V}=0.999$. Mimicking Raffo (2009), we set the investment adjustment costs $\phi$ at 0.55 to match the relative standard deviation of investment with respect to output observed in the data. We also assume that the variance of the IST shock is about three times as big as the one characterizing the TFP shocks, so that IST shocks explain most of the fluctuation in the model's endogenous variables. We still do not consider endogenous capital utilization. Results are reported in the third row (M2) of the mentioned tables. This shock appears to be the "silver bullet" needed to successfully address the four puzzles in the literature. Namely, consumption across countries is less correlated than output, the volatility of the RER increases significantly, and both the "international comovement" and "Backus-Smith" puzzle are effectively solved.

The intuition for this result is provided in Figure 1 (refer to the thick solid line), which plots the impulse response function to this IST shock (one standard deviation increase). As the IST shock hits the home-country, the domestic investment demand significantly increases. Given the aggregate resource constraint, home-country consumption decreases to accommodate the increase in investment demand. Since home investment goods are produced using foreign intermediate goods, the price of intermediate goods produced in the foreign country increases, causing a significant depreciation of the RER in the home economy (i.e., RER increases). These cyclical fluctuations in the RER contribute to its increase volatility in the model simulations, which help us to better address the "price" puzzle. In addition, foreign households feel richer because of the improvement in the terms of trade and unlike to their home-country neighbors they consume more (solving the "quantity" puzzle). Consequently, 
cross-country relative consumption and the RER move in opposite directions (solving the "Backus-Smith" puzzle). This demand effect on the terms of trade (and the RER) is enhanced by a supply effect. That is, over time, the investment boom increases the stock of capital available in the home economy. This more capital-intensive technology results in the increasing availability of home-country output, which becomes relatively abundant and further improves the terms of trade for the foreign economy. Foreign households take advantage of this sizable price effect and increase their labor supply and investment, magnifying over time their joint comovement with their home counterparts (solving the "international comovement" puzzle).

If IST shocks are instead transitory, as in Raffo (2009), the investment boom is relatively short-lived. The fourth row (M3) in the mentioned tables reflects this scenario. The thin solid line in Figure 1 graphs the corresponding impulse response. Here we assume that $\rho_{V}=0.97$. A temporary shock dampens the increase in domestic output over time, as well as the demand for foreign goods. The RER does not increase as much, weakening its negative correlation with relative consumption across countries. While the volatility of the RER decreases, the Backus-Smith puzzle is restored.

Raffo (2009) partly solves this problem by adding endogenous capital utilization as in Greenwood et al. (1988). Refer to the fifth row (M4) in the mentioned tables and to the dashed line in Figure 1. Endogenous capital utilization serves as an effective endogenous propagation mechanism that facilitates investment and output expansions in response to shocks. As the demand for foreign intermediates increases due to the home investment boom, on impact, the increase in the exchange rate is larger.

Nonetheless, this mechanism generates other new counterfactuals. Given the resource 
constraint, a strong investment boom reduces consumption in the home economy so that the correlation between consumption and output turns out to be very small. Raffo (2009) addresses this problem using a GHH utility specification, which suppresses the wealth effect responsible for dampening the response of the labor supply to positive productivity innovations or improvements in the terms of trade. Absent this wealth effect in the labor supply, agents in both countries can increase the labor supply (and consumption) in response to shocks. Refer to the last row (M5).

To conclude, in this section we have shown that the IST processeses are able to address the four mentioned puzzles if they are calibrated so as to explain most of the observed macroeconomic fluctuations. In addition, endogenous capital utilization and a GHH utility specification provide extra degrees of freedom to improve the empirical performance of these models. In this next subsection we will show that when we, instead, use the estimated VECM processes to simulate the model, the IST shocks are powerless to solve the puzzles.

Table 6a: Stationary Model Results

\begin{tabular}{lcccccc}
\hline \hline & $S D(Y)$ & $S D(C)^{+}$ & $S D(X)^{+}$ & $S D(N)^{+}$ & $S D(R E R)^{+}$ & $\rho(R E R)$ \\
\hline Data & 1.25 & 0.80 & 3.40 & 0.91 & 4.28 & 0.84 \\
(M1) Baseline Stationary IRBC & 1.12 & 0.54 & 2.51 & 0.31 & 1.41 & 0.75 \\
(M2) M1 with IST $\left(\rho_{V}=0.999\right)$ & 1.08 & 0.88 & 3.40 & 0.63 & 2.08 & 0.65 \\
(M3) M1 with IST $\left(\rho_{V}=0.97\right)$ & 1.23 & 0.90 & 4.41 & 0.83 & 1.52 & 0.64 \\
(M4) M3 with Capital Util. & 2.00 & 0.49 & 4.02 & 0.70 & 1.14 & 0.62 \\
(M5) M4 with GHH Utility & 1.23 & 0.70 & 2.66 & 0.12 & 1.88 & 0.62 \\
\hline \hline
\end{tabular}

+ denotes relative to output. 
Table 6b: Stationary Model Results

\begin{tabular}{lcccc}
\hline \hline & $C O R R(Y, N)$ & $C O R R(Y, C)$ & $C O R R(Y, X)$ & $C O R R\left(R E R, \frac{C}{C^{*}}\right)$ \\
\hline Data & 0.79 & 0.81 & 0.91 & -0.04 \\
(M1) Baseline Stationary IRBC & 0.97 & 0.93 & 0.97 & 0.99 \\
(M2) M1 with IST $\left(\rho_{V}=0.999\right)$ & 0.56 & 0.51 & 0.76 & -0.20 \\
(M3) M1 with IST $\left(\rho_{V}=0.97\right)$ & 0.70 & 0.12 & 0.81 & 0.24 \\
(M4) M3 with Capital Util. & 0.89 & 0.09 & 0.93 & -0.01 \\
(M5) M4 with GHH Utility & 0.99 & 0.77 & 0.87 & -0.13 \\
\hline \hline
\end{tabular}

Table 6c: Stationary Model Results

\begin{tabular}{lcccc}
\hline \hline & $C O R R\left(Y, Y^{*}\right)$ & $C O R R\left(C, C^{*}\right)$ & $C O R R\left(X, X^{*}\right)$ & $C O R R\left(N, N^{*}\right)$ \\
\hline Data & 0.52 & 0.42 & 0.36 & 0.51 \\
(M1) Baseline Stationary IRBC & 0.33 & 0.81 & -0.05 & -0.05 \\
(M2) M1 with IST $\left(\rho_{V}=0.999\right)$ & 0.46 & 0.30 & 0.20 & 0.17 \\
(M3) M1 with IST $\left(\rho_{V}=0.97\right)$ & 0.34 & 0.40 & 0.13 & 0.30 \\
(M4) M3 with Capital Util. & 0.36 & 0.50 & 0.20 & 0.70 \\
(M5) M4 with GHH Utility & 0.61 & 0.66 & 0.18 & \\
\hline \hline
\end{tabular}



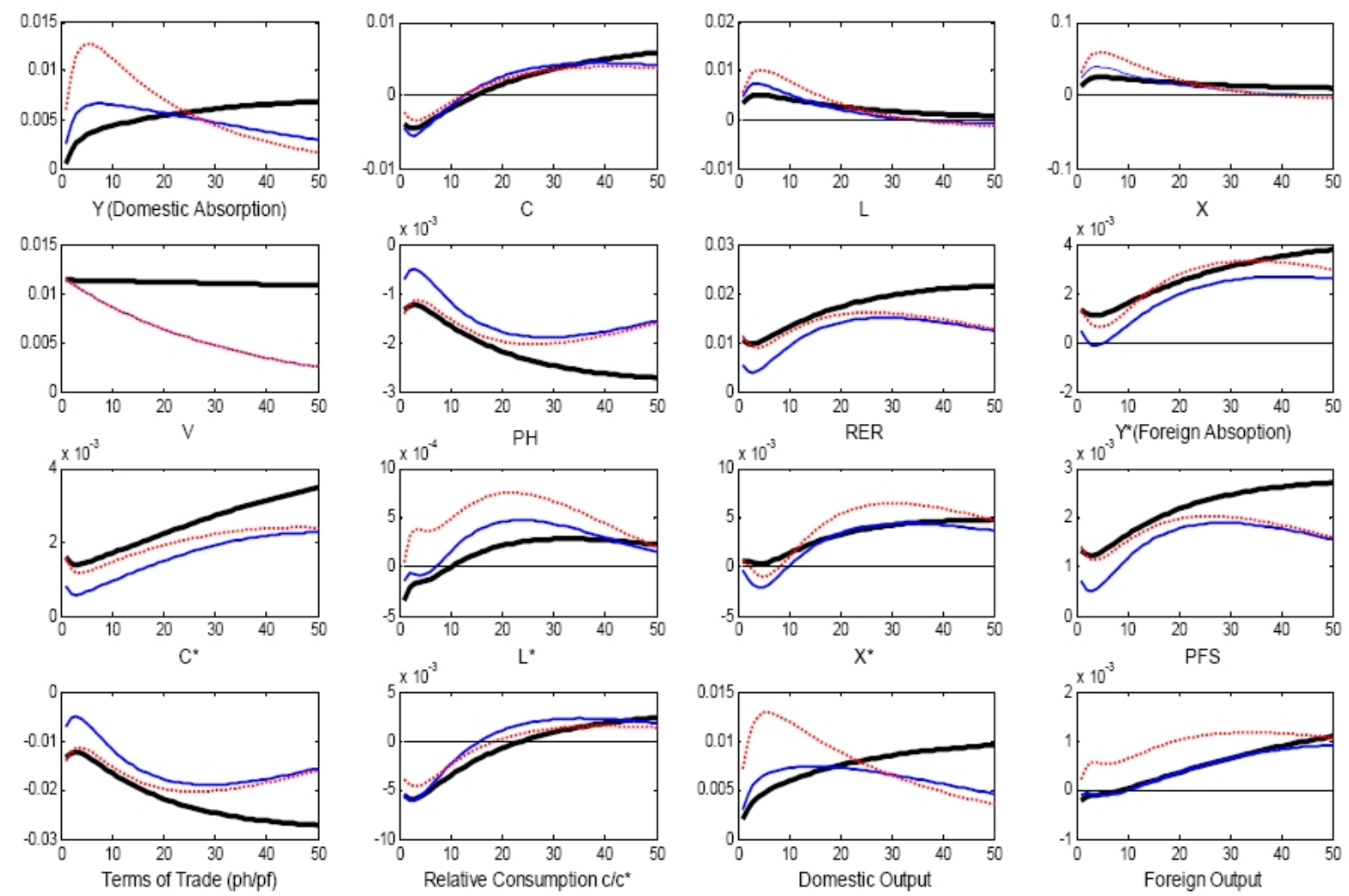

Figure 1. Thick Solid: $\rho_{V}=0.999$. Thin Solid: $\rho=0.97$. Dashed: $\rho=0.97+$ Capital Utilization.

\subsection{IRBC with the Estimated IST Shocks}

Instead of calibrating the IST shocks, in this subsection we simulate the model using the VECM estimates reported in section 3. Hence, we consider the non-stationary version of the model where both TFP and IST shocks are cointegrated. We shall show that when that is the case, the estimated IST innovations fail to solve the existing puzzles. The main reason for this failure is that estimated IST shocks are much less volatile than Raffo (2009) assumes. 
Since our model with the estimated law of motion is non-stationary, we need to rely on simulations to compute the HP-filtered statistics. We HP-filter the relevant series from the model and compute second moments. One might question the use of the HP filter in a model without a stochastic trend. The reason is that we want to replicate patterns studied in the international business cycle literature.

The first two rows in Tables 7(a), 7(b), and 7(c) depict the data and the moments obtained from a standard IRBC with Cobb-Douglas utility (M1) that includes only cointegrated TFP shocks as estimated in Rabanal et al. (2009). As discussed in that paper, the presence of unit root processes in TFP with slow convergence across countries results in very persistent differences in relative productivity that lead to persistent changes in the terms of trade and the RER. As a result, the volatility of this variable increases in the simulations and gets closer in line with the empirical evidence.

In the previous subsection, we showed that an arbitrary near-unit-root IST process with no spillovers across countries was the "silver bullet" needed to solve the four puzzles. Interestingly, our VECM estimates for the IST process imply similar dynamics: (a) IST processes for the U.S. and the ROW are well-characterized by unit roots and (b) the estimated very low speed of convergence $\left(\kappa_{V}, \kappa_{V}^{*}\right)$ of these processes somewhat mimics the scenario with no spillovers in the stationary case. That is, despite the fact that the IST processes for both countries are cointegrated and co-move in the long run, these IST processes will converge very slowly when a shock hits one of the countries. Indeed, the shape of the impulse responses to a non-stationary shock (refer to the solid line in Figure 2) confirms this intuition, since the dynamics resemble those in Figure 1.

However, the quantitative results at the time of comparing the computed moments with 
those obtained from the data are disappointing. In the third row of the mentioned tables, we consider a case with cointegrated IST and TFP (M2). ${ }^{11}$ Both the "quantity" puzzle and "Backus-Smith" puzzle remain in place. In addition, and opposite to the empirical evidence, the volatility of the RER and the comovement of factor inputs decrease. Results with endogenous capital utilization (fourth row, M3, and the dashed line in Figure 2) or GHH utility (fifth row, M4) specifications are similarly disappointing.

Why do our estimated IST processes generate such different results despite the fact that they lead to dynamics similar to the ones discussed in the stationary case? In the previous section, we followed Raffo (2009) and fixed the standard deviation of the IST shocks to be about three times as large as the one characterizing the TFP shock. In the data, the standard deviation of both techonological processes is about of the same magnitude. Actually, when non-stationary shocks are in place, we need to multiply the standard deviation of the IST shock by a factor of 6 , and set capital adjustment costs, $\phi$, equal to 6 , in order to properly address the puzzles. The last row (M5) of these tables depicts this case. This arbitrary specification is sufficient to solve all the puzzles, though the "quantity" puzzle remains in place.

\footnotetext{
${ }^{11}$ Note that in this case we do not consider investment adjusment costs. Since our estimated IST shocks have a smaller variance than the ones used by Raffo (2009) we do not need to include them to dampen the response of investment. Actually, zero adjustment costs will deliver a relative standard deviation of investment that is lower than the one observed in the data.
} 
Table 7a: Non-Stationary Model Results

\begin{tabular}{|c|c|c|c|c|c|c|}
\hline & $S D(Y)$ & $S D(C)^{+}$ & $S D(X)^{+}$ & $S D(N)^{+}$ & $S D(R E R)^{+}$ & $\rho(R E R)$ \\
\hline Data & 1.25 & 0.80 & 3.40 & 0.91 & 4.28 & 0.84 \\
\hline (M1) Cointegrated TFP only & 0.70 & 0.62 & 2.31 & 0.28 & 4.26 & 0.70 \\
\hline (M2) Cointegrated TFP and IST & 0.75 & 0.72 & 2.99 & 0.50 & 3.89 & 0.72 \\
\hline (M3) M2 with Capital Util. & 1.07 & 0.60 & 2.81 & 0.48 & 2.90 & 0.70 \\
\hline (M4) M3 with GHH utility & 0.79 & 0.79 & 2.31 & 0.15 & 3.41 & 0.73 \\
\hline (M5) M3 with High SD for IST & 1.39 & 0.76 & 3.68 & 0.74 & 3.13 & 0.73 \\
\hline
\end{tabular}

${ }^{+}$denotes relative to output.

Table 7b: Non-Stationary Model Results

\begin{tabular}{lcccc}
\hline \hline & $C O R R(Y, N)$ & $C O R R(Y, C)$ & $C O R R(Y, X)$ & $C O R R\left(R E R, \frac{C}{C^{*}}\right)$ \\
\hline Data & 0.79 & 0.81 & 0.91 & -0.04 \\
(M1) Cointegrated TFP only & 0.92 & 0.93 & 0.95 & 0.97 \\
(M2) Cointegrated TFP and IST & 0.70 & 0.64 & 0.85 & 0.72 \\
(M3) M2 with Capital Util. & 0.81 & 0.65 & 0.91 & 0.82 \\
(M4) M3 with GHH utility & -0.30 & 0.79 & 0.85 & 0.60 \\
(M5) M3 with High SD for IST & 0.73 & 0.20 & 0.86 & -0.02 \\
\hline \hline
\end{tabular}


Table 7c: Non-Stationary Model Results

\begin{tabular}{lcccc}
\hline \hline & $C O R R\left(Y, Y^{*}\right)$ & $C O R R\left(C, C^{*}\right)$ & $C O R R\left(X, X^{*}\right)$ & $C O R R\left(N, N^{*}\right)$ \\
\hline Data & 0.52 & 0.42 & 0.36 & 0.51 \\
(M1) Cointegrated TFP only & 0.38 & 0.63 & 0.05 & 0.16 \\
(M2) Cointegrated TFP and IST & 0.42 & 0.50 & 0.06 & 0.05 \\
(M3) M2 with Capital Util. & 0.40 & 0.67 & 0.07 & -0.19 \\
(M4) M3 with GHH utility & 0.43 & 0.43 & 0.21 & 0.32 \\
(M5) M3 with High SD for IST & 0.40 & 0.60 & 0.20 & \\
\hline \hline
\end{tabular}
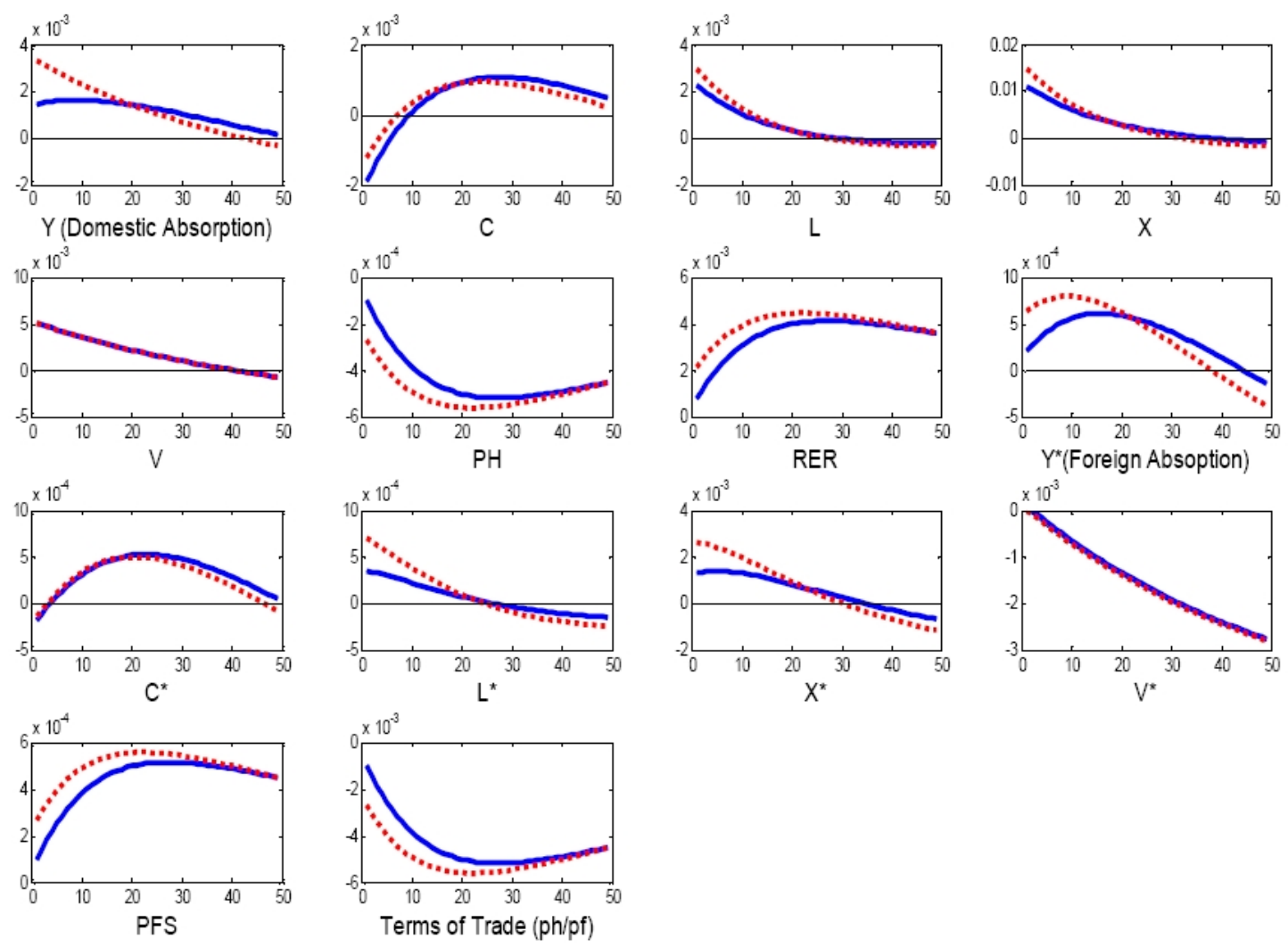

Figure 2: Solid: Non-Stationary IST shock. Dashed: Same with Capital Utilization. 


\section{Concluding Remarks}

Standard IRBC models with TFP shocks fail to account for some important features of the data. In particular, there are four puzzles that are robust to different model specifications and contradict the empirical evidence. First, risk sharing induces very strong positive crosscountry consumption correlations, even when only incomplete markets are considered (quantity puzzle). Second, the RER is much more volatile in the data than in these models (price puzzle). Third, the equilibrium RER is closely related to the ratio of consumption across the two economies, opposite to the evidence (Backus-Smith puzzle). Finally, these models predict a counterfactual negative cross-country correlation of investment and employment (international comovement puzzle).

The literature has been trying to fill the gap between theory and data. One alternative to address the discrepancies between the model and the data consists of focusing on IST shocks. Raffo (2009) shows that thoughtfully parameterized IST shocks are sufficient to fill the gap.

However, the IST shocks also have a direct link to the data. In this paper, we use OECD data to characterize the IST shocks and estimate a VECM that characterizes their law of motion. Simulations of a model parameterized using these estimates do not support the results in Raffo (2009). The reason behind this discrepancy is that Raffo (2009) calibrates the standard deviations of his IST shocks to be around three times larger than its empirical equivalent as we estimate them (so that Raffo's (2009) IST shocks explain about two thirds of the variability of output). Moreover, when non-stationary shocks are in place, we need to multiply the standard deviation of the IST shock by a factor of six, in order to properly address the puzzles. 


\section{References}

[1] Altig, D., L. Christiano, M. Eichenbaum, and J. Lindé, 2005, "Firm-Specific Capital, Nominal Rigidities and the Business Cycle," NBER Working Paper No. 11034.

[2] Backus, D., P. Kehoe and F. Kydland, 1992, "International Business Cycles," Journal of Political Economy, Vol. 100, 745 -775.

[3] Backus, D. and G. Smith, 1993, "Consumption and Real Exchange Rates in Dynamic Economies with Non-traded Goods," Journal of International Economics, Vol. 35, 297316.

[4] Basu, S. and M. Kimball, 1997, "Cyclical Productivity with Unobserved Input Variation," NBER Working Paper No. 5915.

[5] Baxter, M., 1995, "International Trade and Business Cycles," NBER Working Paper No. 5025.

[6] Baxter, M. and M. Crucini, 1995, "Business Cycles and the Asset Structure of Foreign Trade," International Economic Review, Vol. 36, 821-854.

[7] Baxter, M. and D. Farr, 2001, "Variable Factor Utilization and International Business Cycle," NBER Working Paper No. 8392.

[8] Chari, V.V. , P. Kehoe and E. McGrattan, 2002, "Can Sticky Price Models Generate Volatile and Persistent Real Exchange Rates?," Review of Economic Studies, Vol. 69, $533-563$. 
[9] Corsetti, G., L. Dedola and S. Leduc, 2008a, "International Risk Sharing and the Transmission of Productivity Shocks," Review of Economic Studies, Vol. 75, 443-473.

[10] Corsetti, G., L. Dedola and S. Leduc, 2008b, "High Exchange Rate Volatility and Low Pass-through," Journal of Monetary Economics, Vol. 55, 1113-1128.

[11] Elliott, G., T. Rothenberg and J. Stock, 1996, "Efficient Tests for an Autoregressive Unit Root," Econometrica, Vol. 64, 813-836.

[12] Engle R. and C. Granger, 1987, "Co-Integration and Error Correction: Representation, Estimation, and Testing," Econometrica, Vol. 55, 251-276.

[13] Engel, C. and A. Matsumoto, 2009, "The International Diversification Puzzle When Goods Prices Are Sticky: It's Really about Exchange-Rate Hedging, Not Equity Portfolios," American Economic Journal: Macroeconomics, Vol. 1, 155-88.

[14] Fisher, J., 2006, "The Dynamic Effects of Neutral and Investment-Specific Technology Shocks, " Journal of Political Economy, Vol. 114, 413-451.

[15] Greenwood, J., Z. Hercowitz, and G. Huffman, 1988, "The Role of Investment-Specific Technological Change in the Business Cycle," European Economic Review, Vol. 44, $91-115$.

[16] Heathcote, J., and F. Perri, 2002, "Financial Autarky and International Business Cycles," Journal of Monetary Economics, Vol. 49, 601-627.

[17] Heathcote, J., and F. Perri, 2007, "The International Diversification Puzzle Is Not as Bad as You Think," NBER Working Paper No. 13483. 
[18] Ireland, P., 2009, "Stochastic Growth in the United States and the Euro Area," Boston College Working Papers in Economics No. 713.

[19] Johansen, S., 1991, "Estimation and Hypothesis Testing of Cointegration Vectors in Gaussian Vector Autoregressive Models," Econometrica Vol. 59, 1551-1580.

[20] Justiniano, A., G. Primicieri and A. Tambalotti, 2008, "Investment Shocks and Business Cycles," Federal Reserve Bank of New York Staff Report No. 322.

[21] King, R., C., Plosser and S., Rebelo, 1988, "Production, Growth and the Business Cycle," Journal of Monetary Economics, Vol. 21, 195-232.

[22] Ng, S. and P. Perron, 2001, "LAG Length Selection and the Construction of Unit Root Tests with Good Size and Power," Econometrica Vol. 69, 1519-1554.

[23] Rabanal, P., J. Rubio-Ramírez, and V. Tuesta, 2009, "Cointegrated TFP Processes and International Business Cycles," International Monetary Fund Working Paper 09/212.

[24] Raffo, A., 2008, "Net exports, Consumption Volatility and International Business Cycle Models," Journal of International Economics, Vol. 75, 14-29.

[25] Raffo, A., 2009, "Technology Shocks: Novel Implications for International Business Cycles", mimeo.

[26] Schmitt-Grohé, S and M. Uribe, 2008, "What's News in Business Cycles, " NBER Working Paper No. 14215. 
[27] Stockman, A., L. Tesar, 1995, "Tastes and Technology in a Two-Country Model of the Business Cycle: Explaining International Comovements," American Economic Review, Vol. 85, 165-185. 


\section{A. Appendix}

\section{A.1. Normalized Equilibrium Conditions}

In this Appendix we analyze the case of Cobb-Douglas utility function. For simplicity in the exposition, redefine $x\left(s^{t_{s}}\right)$ as $x_{t_{s}}$ and $\sum_{s^{t+1}} \pi\left(s^{t+1} / s^{t}\right)\{\}$ as $E_{t}\{\}$. Since the presence of two

unit roots makes the model non-stationary, we rescale the variables by $\hat{Y}_{t}=\frac{Y_{t}}{Z_{t-1}}, \hat{C}_{t}=\frac{C_{t}}{Z_{t-1}}$, $\hat{X}_{t}=\frac{X_{t}}{Z_{t-1}}$, and $\hat{K}_{t-1}=\frac{K_{t-1}}{Z_{t-1} V_{t-1}}$ where $Z_{t}=A_{t}^{\frac{1}{1-\alpha}} V_{t}^{\frac{\alpha}{1-\alpha}}$. Similar normalizations will hold for the foreign-country.

Market clearing for the intermediate goods:

$$
\begin{aligned}
\hat{Y}_{H, t}+\hat{Y}_{H, t}^{*} & =\left(\frac{A_{t}}{A_{t-1}}\right)\left(\hat{K}_{t-1}^{d}\right)^{\alpha}\left(L_{t}\right)^{1-\alpha} \\
\hat{Y}_{F, t}+\hat{Y}_{F, t}^{*} & =\left(\frac{A_{t}^{*}}{A_{t-1}^{*}}\right)\left(\hat{K}_{t-1}^{*, d}\right)^{\alpha}\left(L_{t}^{*}\right)^{1-\alpha}
\end{aligned}
$$

Production function of the final good:

$$
\begin{gathered}
\hat{Y}_{t}=\left[\omega^{\frac{1}{\theta}} \hat{Y}_{H, t}^{\frac{\theta-1}{\theta}}+(1-\omega)^{\frac{1}{\theta}} \hat{Y}_{F, t}^{\frac{\theta-1}{\theta}}\left(\frac{Z_{t-1}^{*}}{Z_{t-1}}\right)^{\frac{\theta-1}{\theta}}\right]^{\frac{\theta}{\theta-1}} \\
\widehat{Y}_{t}^{*}=\left[\omega^{\frac{1}{\theta}} \widehat{Y}_{F, t}^{* \frac{\theta-1}{\theta}}+(1-\omega)^{\frac{1}{\theta}} \widehat{Y}_{H, t}^{*} \frac{\theta-1}{\theta}\left(\frac{Z_{t-1}}{Z_{t-1}^{*}}\right)^{\frac{\theta-1}{\theta}}\right]^{\frac{\theta}{\theta-1}}
\end{gathered}
$$

Market clearing final good:

$$
\begin{aligned}
\hat{Y}_{t} & =\hat{C}_{t}+\hat{X}_{t} \\
\hat{Y}_{t}^{*} & =\hat{C}_{t}^{*}+\hat{X}_{t}^{*}
\end{aligned}
$$


Labor supply:

$$
\begin{aligned}
& \frac{1-\gamma}{\gamma} \frac{\hat{C}_{t}}{\left(1-L_{t}\right)}=\hat{W}_{t} \\
& \frac{1-\gamma}{\gamma} \frac{\hat{C}_{t}^{*}}{\left(1-L_{t}^{*}\right)}=\hat{W}_{t}^{*}
\end{aligned}
$$

Marginal utility of consumption:

$$
\begin{aligned}
& \hat{\lambda}_{t}=\frac{\gamma}{\hat{C}_{t}}\left\{\hat{C}_{t}^{\gamma}\left(1-L_{t}\right)^{1-\gamma}\right\}^{1-\sigma} \\
& \hat{\lambda}_{t}^{*}=\frac{\gamma}{\hat{C}_{t}^{*}}\left\{\left(\hat{C}_{t}^{*}\right)^{\gamma}\left(1-L_{t}^{*}\right)^{1-\gamma}\right\}^{1-\sigma}
\end{aligned}
$$

where $\hat{\lambda}_{t}=\lambda_{t} Z_{t-1}^{1-\gamma(1-\sigma)}$ and $\hat{\lambda}_{t}^{*}=\lambda_{t}^{*} Z_{t-1}^{* 1-\gamma(1-\sigma)}$.

Risk-sharing

$E_{t}\left\{\frac{\hat{\lambda}_{t+1}^{*}}{\hat{\lambda}_{t}^{*}}\left[\left(\frac{Z_{t-1}^{*}}{Z_{t}^{*}}\right)^{1-\gamma(1-\sigma)}\right] \frac{\widetilde{P}_{H, t+1}}{\widetilde{P}_{H, t}} \frac{R E R_{t}}{R E R_{t+1}}\right\}=E_{t}\left\{\left[\frac{\hat{\lambda}_{t+1}}{\hat{\lambda}_{t}}\left(\frac{Z_{t-1}}{Z_{t}}\right)^{1-\gamma(1-\sigma)}\right] \frac{\widetilde{P}_{H, t+1}}{\widetilde{P}_{H, t}}\right\}-\frac{\phi}{\beta} \hat{D}_{t}$

where $\hat{D}_{t}=\left(\frac{D_{t}-D}{Z_{t-1}}\right)$.

The price of the bond

$$
\bar{Q}_{t}=\beta E_{t}\left\{\frac{\hat{\lambda}_{t+1}}{\hat{\lambda}_{t}}\left(\frac{Z_{t-1}}{Z_{t}}\right)^{1-\gamma(1-\sigma)} \frac{\widetilde{P}_{H, t+1}}{\widetilde{P}_{H, t}}\right\}-\phi \hat{D}_{t}
$$


Euler Equations:

$$
\begin{aligned}
\hat{\lambda}_{t} & =\hat{\mu}_{t} \frac{V_{t}}{V_{t-1}}\left(1-\phi\left(\frac{\hat{X}_{t}}{\hat{X}_{t-1}} \frac{Z_{t-1}}{Z_{t-2}}-\Lambda_{X}\right)\right)+\beta E_{t} \hat{\mu}_{t+1}\left(\frac{Z_{t}}{Z_{t-1}}\right)^{1-\gamma(1-\sigma)} \frac{V_{t+1}}{V_{t}}[(*)] \\
{[(*)]=} & {\left[\phi\left(\frac{\hat{X}_{t+1}}{\hat{X}_{t}} \frac{Z_{t}}{Z_{t-1}}-\Lambda_{X}\right) \frac{\hat{X}_{t+1}}{\hat{X}_{t}} \frac{Z_{t}}{Z_{t-1}}-\frac{\phi}{2}\left(\frac{\hat{X}_{t+1}}{\hat{X}_{t}} \frac{Z_{t}}{Z_{t-1}}-\Lambda_{X}\right)^{2}\right] } \\
\hat{\lambda}_{t}^{*}= & \hat{\mu}_{t}^{*} \frac{V_{t}^{*}}{V_{t-1}^{*}}\left(1-\phi\left(\frac{\hat{X}_{t}^{*}}{\hat{X}_{t-1}^{*}} \frac{Z_{t-1}^{*}}{Z_{t-2}^{*}}-\Lambda_{X}^{*}\right)\right)+\beta E_{t} \hat{\mu}_{t+1}^{*}\left(\frac{Z_{t}^{*}}{Z_{t-1}^{*}}\right)^{1-\gamma(1-\sigma)} \frac{V_{t+1}^{*}}{V_{t}^{*}[(*)]} \\
{[(*)]=} & {\left.\left[\frac{\hat{X}_{t+1}^{*}}{\hat{X}_{t}^{*}} \frac{Z_{t}^{*}}{Z_{t-1}^{*}}-\Lambda_{X}^{*}\right) \frac{\hat{X}_{t+1}^{*}}{\hat{X}_{t}^{*}} \frac{Z_{t}^{*}}{Z_{t-1}^{*}}-\frac{\phi}{2}\left(\frac{\hat{X}_{t+1}^{*}}{\hat{X}_{t}^{*}} \frac{Z_{t}^{*}}{Z_{t-1}^{*}}-\Lambda_{X}^{*}\right)^{2}\right] }
\end{aligned}
$$

where $\hat{\mu}_{t}=V_{t-1} Z_{t-1}^{1-\gamma(1-\sigma)} \mu_{t}$ and $\hat{\mu}_{t}^{*}=V_{t-1}^{*}\left(Z_{t-1}^{*}\right)^{1-\gamma(1-\sigma)} \mu_{t}^{*}$.

$$
\begin{aligned}
& \frac{V_{t}}{V_{t-1}}\left(\frac{Z_{t}}{Z_{t-1}}\right)^{1-\gamma(1-\sigma)} \hat{\mu}_{t}=\beta E_{t}\left\{u_{t+1} \hat{R}_{t+1} \hat{\lambda}_{t+1}+\hat{\mu}_{t+1}\left(1-\delta\left(u_{t+1}\right)\right)\right\} \\
& \frac{V_{t}^{*}}{V_{t-1}^{*}}\left(\frac{Z_{t}^{*}}{Z_{t-1}^{*}}\right)^{1-\gamma(1-\sigma)} \hat{\mu}_{t}^{*}=\beta E_{t}\left\{u_{t+1}^{*} \hat{R}_{t+1}^{*} \hat{\lambda}_{t+1}^{*}+\hat{\mu}_{t+1}^{*}\left(1-\delta^{*}\left(u_{t+1}^{*}\right)\right)\right\}
\end{aligned}
$$

where $\hat{R}_{t}=R_{t} V_{t-1}$ and $\hat{R}_{t}^{*}=R_{t}^{*} V_{t-1}^{*}$ 
Capital Accumulation $\left(\hat{K}_{t-1}=\frac{K_{t-1}}{Z_{t-1} V_{t-1}}\right)$

$$
\begin{aligned}
\hat{K}_{t} \frac{Z_{t}}{Z_{t-1}} \frac{V_{t}}{V_{t-1}} & =\left(1-\delta\left(u_{t}\right)\right) \hat{K}_{t-1}+\frac{V_{t}}{V_{t-1}}\left(\hat{X}_{t}-\frac{\phi}{2} \frac{Z_{t-2}}{Z_{t-1}} \hat{X}_{t-1}\left[\frac{\hat{X}_{t}}{\hat{X}_{t-1}} \frac{Z_{t-1}}{Z_{t-2}}-\Lambda_{X}\right]^{2}\right) \\
\hat{K}_{t}^{*} \frac{Z_{t}^{*}}{Z_{t-1}^{*}} \frac{V_{t}^{*}}{V_{t-1}^{*}} & =\left(1-\delta\left(u_{t}^{*}\right)\right) \hat{K}_{t-1}^{*}+\frac{V_{t}^{*}}{V_{t-1}^{*}}\left(\hat{X}_{t}^{*}-\frac{\phi}{2} \frac{Z_{t-2}^{*}}{Z_{t-1}^{*}} X_{t-1}^{*}\left[\frac{\hat{X}_{t}^{*}}{\hat{X}_{t-1}^{*}} \frac{Z_{t-1}^{*}}{Z_{t-2}^{*}}-\Lambda_{X}^{*}\right]^{2}\right)
\end{aligned}
$$

Real wages and rental rates of capital:

$$
\begin{aligned}
\alpha \hat{W}_{t} L_{t} & =(1-\alpha) \hat{K}_{t-1} \hat{R}_{t} \\
\alpha \hat{W}_{t}^{*} L_{t}^{*} & =(1-\alpha) \hat{K}_{t-1}^{*} \hat{R}_{t}^{*} \\
\hat{W}_{t} & =(1-\alpha) \widetilde{P}_{H, t}\left(\hat{K}_{t-1}^{d}\right)^{\alpha}\left(\frac{A_{t}}{A_{t-1}}\right) L_{t}^{-\alpha} \\
\hat{W}_{t}^{*} & =(1-\alpha) \widetilde{P}_{F, t}^{*}\left(\hat{K}_{t-1}^{d, *}\right)^{\alpha}\left(\frac{A_{t}^{*}}{A_{t-1}^{*}}\right)\left(L_{t}^{*}\right)^{-\alpha} \\
\hat{\lambda}_{t} \hat{R}_{t} & =b \hat{\mu}_{t} u_{t}^{\varepsilon} \\
\hat{\lambda}_{t}^{*} \hat{R}_{t}^{*} & =b \hat{\mu}_{t}^{*}\left(u_{t}^{*}\right)^{\varepsilon} \\
\delta_{t} & =\hat{\delta}+\frac{b}{1+\varepsilon} u_{t}^{1+\varepsilon} . \\
\delta_{t}^{*} & =\hat{\delta}+\frac{b}{1+\varepsilon}\left(u_{t}^{*}\right)^{1+\varepsilon} .
\end{aligned}
$$

Finally, let us give a look to the demand functions:

$$
\begin{gathered}
\hat{Y}_{H, t}=\omega\left(\widetilde{P}_{H, t}\right)^{-\theta} \hat{Y}_{t} \\
\hat{Y}_{F, t}=(1-\omega)\left(\widetilde{P}_{F, t}^{*} R E R_{t}\right)^{-\theta} \hat{Y}_{t} \frac{Z_{t-1}}{Z_{t-1}^{*}}
\end{gathered}
$$


Proceeding in a similar way, we get the demands for the foreign-country:

$$
\begin{aligned}
\widehat{Y}_{H, t}^{*} \frac{Z_{t-1}}{Z_{t-1}^{*}} & =(1-\omega)\left(\frac{\widetilde{P}_{H, t}}{R E R_{t}}\right)^{-\theta} \widehat{Y}_{t}^{*} \\
\widehat{Y}_{F, t}^{*} & =\omega\left(\widetilde{P}_{F, t}^{*}\right)^{-\theta} \widehat{Y}_{t}^{*}
\end{aligned}
$$

Auxiliary variable:

$$
n x_{t}=\frac{\widetilde{P}_{H, t} \hat{Y}_{H, t}^{*}-\widetilde{P}_{F, t}^{*} R E R_{t} \hat{Y}_{F, t}\left(\frac{Z_{t-1}^{*}}{Z_{t-1}}\right)}{\hat{Y}_{t}}
$$

The law of motion of the bond is:

$$
\widetilde{P}_{H, t} \bar{Q}_{t} \hat{D}_{t}=\widetilde{P}_{H, t} \hat{Y}_{H, t}^{*}-\widetilde{P}_{F, t}^{*} R E R_{t} \hat{Y}_{F, t}\left(\frac{Z_{t-1}^{*}}{Z_{t-1}}\right)+\tilde{P}_{H, t} \hat{D}_{t-1} \frac{Z_{t-2}}{Z_{t-1}}-\tilde{P}_{H, t} \frac{\phi}{2}\left(\hat{D}_{t}\right)^{2}
$$

Supplementary equation:

$$
\hat{K}_{t-1}^{d}=u_{t} \hat{K}_{t-1,} \quad \hat{K}_{t-1}^{d, *}=u_{t}^{*} \hat{K}_{t-1}^{*}
$$

\section{A.2. GHH Utility Specification}

We now analyze the GHH specification. The utility function is:

$$
\frac{\left\{C_{t}-\psi Z_{t-1} L_{t}^{\nu}\right\}^{1-\sigma}}{1-\sigma}
$$

where, as standard, we augment the GHH preferences by $Z_{t-1}$ to obtain a formulation that is consistent with balanced growth. The FOC's are respectively replaced as follows: 


$$
\begin{gathered}
\psi Z_{t-1} \nu L_{t}^{\nu-1}=W_{t} \\
{\left[C_{t}-\psi Z_{t-1} L_{t}^{\nu}\right]^{-\sigma}=\lambda_{t}}
\end{gathered}
$$

Non-Stationary case Notice that for the non-stationary case, we have the following:

$$
\begin{gathered}
\psi \nu L_{t}^{\nu-1}=\hat{W}_{t} \\
{\left[\hat{C}_{t}-\psi L_{t}^{\nu}\right]^{-\sigma}=\hat{\lambda}_{t}}
\end{gathered}
$$

Where $\hat{\lambda}_{t}=\lambda_{t} Z_{t-1}^{\sigma}$. 